\title{
Inflammation Triggered by SARS-CoV-2 and ACE2 Augment Drives Multiple Organ Failure of Severe COVID-19: Molecular Mechanisms and Implications
}

\author{
Masae Iwasaki, ${ }^{1,2}$ Junichi Saito, ${ }^{1,3}$ Hailin Zhao, ${ }^{1}$ Atsuhiro Sakamoto, ${ }^{2}$ Kazuyoshi Hirota, ${ }^{3}$ and \\ Daqing $M a \mathbb{D}^{1,4}$
}

Received July 24, 2020; accepted August 31, 2020

Abstract - The widespread occurrence of severe acute respiratory syndrome coronavirus 2 (SARS-CoV-2) has led to a pandemic of coronavirus disease 2019 (COVID-19). The S spike protein of SARS-CoV-2 binds with angiotensin-converting enzyme 2 (ACE2) as a functional "receptor" and then enters into host cells to replicate and damage host cells and organs. ACE2 plays a pivotal role in the inflammation, and its downregulation may aggravate COVID-19 via the renin-angiotensin system, including by promoting pathological changes in lung injury and involving inflammatory responses. Severe patients of COVID-19 often develop acute respiratory distress syndrome and multiple organ dysfunction/failure with high mortality that may be closely related to the hyper-proinflammatory status called the "cytokine storm." Massive cytokines including interleukin-6, nuclear factor kappa B (NFkB), and tumor necrosis factor alpha (TNF $\alpha)$ released from SARS-CoV-2-infected macrophages and monocytes lead inflammation-derived injurious cascades causing multi-organ injury/failure. This review summarizes the current evidence and understanding of the underlying mechanisms of SARS-CoV-2, ACE2 and inflammation co-mediated multi-organ injury or failure in COVID19 patients.

KEY WORDS: SARS-CoV-2; COVID-19; angiotensin-converting enzyme 2; renin-angiotensin system; cytokine storm; multiple organ failure.

MI and JS contributed equally to this work and are co-first authors.

\footnotetext{
${ }^{1}$ Division of Anaesthetics, Pain Medicine and Intensive Care, Department of Surgery and Cancer, Faculty of Medicine, Imperial College London, Chelsea and Westminster Hospital, London, UK

${ }^{2}$ Department of Anesthesiology and Pain Medicine, Graduate School of Medicine, Nippon Medical School, Tokyo, Japan

${ }^{3}$ Department of Anesthesiology, Hirosaki University Graduate School of Medicine, Hirosaki, Aomori, Japan

${ }^{4}$ To whom correspondence should be addressed at Division of Anaesthetics, Pain Medicine and Intensive Care, Department of Surgery and Cancer, Faculty of Medicine, Imperial College London, Chelsea and Westminster Hospital, London, UK. E-mail: d.ma@imperial.ac.uk
}

\section{INTRODUCTION}

Coronavirus disease-2019 (COVID-19) is a highly transmissible disease caused by severe acute respiratory syndrome coronavirus-2 (SARS-CoV-2). The majority of COVID-19 patients have only mild symptoms and do not need hospitalization [48, 179]. Compared to the outbreaks of severe acute respiratory syndrome (SARS; 2002-2003; 774 deaths/8096 cases, case fatality rate (CFR) 9.6\%) and Middle East respiratory syndrome (MERS; 
Iwasaki, Saito, Zhao, Sakamoto, Hirota, and Ma

2012-ongoing; 858 deaths/2494 cases, CFR 34.4\%), the CFR of COVID-19 is relatively low $(333,401$ deaths $/ 5,103,006$ cases, CFR 6.5\%) (recorded on May 23, 2020), but SARS-CoV-2 infection has caused the worst death toll worldwide [179]. Indeed, a certain percentage of COVID-19 patients (approx. $5 \%$ ) were severe cases and often developed acute respiratory distress syndrome (ARDS), systemic inflammatory response syndrome (SIRS), and multiple organ dysfunction/failure with high mortality (CFR 49\%) [179]. It has been suggested that respiratory failure associated with ARDS is the leading cause of death in COVID-19 cases [132].

The severity of COVID-19 is correlated with the levels of interleukin (IL)-6, C-reactive protein (CRP), and other proinflammatory cytokines [132, 175]. It was also found that the combination of D-dimer and IL-6 can be used to distinguish severe COVID-19 patients (area under the receiver operating characteristic [ROC] curve: 0.840) [39], suggesting that the high mortality rate of COVID-19 might be caused by the subsequent SIRS induced by a "cytokine storm." It has been indicated that early interventions to attenuate this cytokine storm may improve the clinical outcomes of severe cases of COVID-19 [185].

Angiotensin-converting enzyme (ACE) 2 is a common binding site ("receptor") for both SARS$\mathrm{CoV}$ and SARS-CoV-2 [60]. The SARS-CoV-2 entry into host cells begins with its viral spike (S) protein binding to the host cell's surface transmembrane ACE2, followed by a downregulation of membrane ACE2 expression [74]. The normal level of ACE2 is important to protect vital organs; However, as demonstrated in the models of acute lung injury (ALI) and ARDS [53, 62], the abnormal ACE2 levels were suggested to aggravate COVID-19 via the reninangiotensin system (RAS), including promoting pathological changes in ALI [62] and being involved in inflammatory and fibrotic responses [141]. ACE2 may thus be a key disease mediator in the pathogenesis of COVID-19. Indeed, a recent publication indicated that higher ACE2 concentrations led to increased vulnerability to SARS-CoV-2 infection in men compared to women, and that this finding was also associated with the higher incidence and fatality rate of COVID-19 in men [133]. This review aims to summarize the multi-organ injuries and failure and the underlying mechanisms of COVID-19 that are associated with SARS-CoV-2 infection via ACE2 entry route and beyond.

\section{THE PHYSIOLOGY OF THE RENIN- ANGIOTENSIN SYSTEM AND ACE2}

\section{The Systemic "Classic" Functions of RAS}

As illustrated in Fig. 1, ACE2 is a key enzyme in the RAS, with multiple physiological functions [60]. The RAS is known as a major regulator of a wide range of physiology and pathophysiology $[38,118]$ such as the mediation of fluid/electrolyte homeostasis and the maintenance of vascular tone via angiotensin type 1 receptor (AT1R) in vital organs (kidneys, vascular smooth muscle, lung, heart, brain, adrenals, pituitary gland, and liver) [53]. For example, when the renal blood flow is reduced, the kidneys' juxtaglomerular cells secrete renin directly into the blood circulation. This secreted renin converts angiotensinogen released by the liver to be angiotensin1 (Ang1), which is then converted to be angiotensin2 (Ang2) by ACE in pulmonary vascular endothelial cells [117, 118, 123]. Ang2 plays a central role in the RAS by acting on the angiotensin type 2 receptors AT1R and AT2R.

\section{The Local "Tissue" and "Intracellular" RAS}

In addition to the systemic RAS, the physiological functions of RAS can been seen at the local "tissue" and even "intracellular" levels in the heart, lung, brain, kidney, liver, intestine and other digestive system [77, $82,117]$. The tissue RAS is involved mainly in cardiovascular regulation and inflammatory processes such as vascular permeability and tone [117] and cell apoptosis [25], growth [26], migration [26], and differentiation [27, 94]. The intracellular RAS is involved in the intracellular signaling pathways; Ang2 stimulates the production of reactive oxygen species (ROS) and nuclear factor kappa B (NFKB) via AT1R and the phosphatidylinositol-4,5-bisphosphate 3-kinase/protein kinase B (PI3K/Akt) pathway, leading to increases of proinflammatory cytokines such as IL-6, chemokines, and adhesion molecules in tissue-resident cells in the amplifying inflammatory cycle [38].

\section{ACE2, Angiotensin-(1-7), and the Mas Receptor Axis: Anti-inflammatory Property}

ACE2 exists in two forms, the full-length transmembrane ACE2 (ACE2) and the soluble ACE2 (sACE2). SACE2 is cleaved from ACE2 by ADAM17 (a disintegrin and metallopeptidase domain 17) and then released into the extracellular environment [79]. ACE2 is the predominant enzyme regulating the ACE2/Ang-(1-7)/Mas receptor 


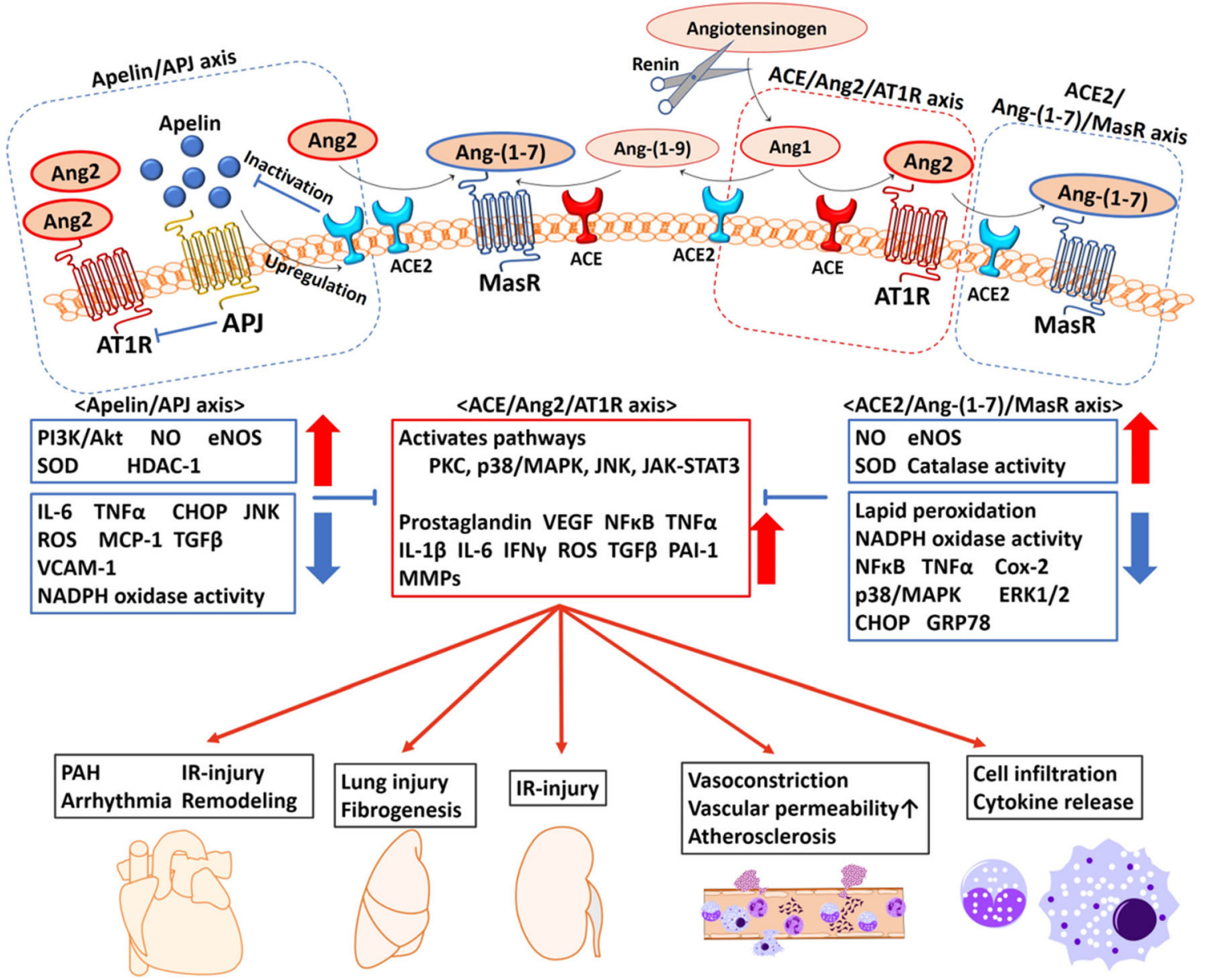

Fig. 1. The enzymatic cascade and the apelin/APJ axis in the renin-angiotensin system (RAS). Multiple biological effects of RAS are mediated by Ang2, Ang-(1-7), and apelin. Ang2 is a central regulator of the inflammatory response, mainly through AT1R. As a proinflammatory modulator, Ang2 interacts on both immune cells and tissue-resident cells. The activated synthesis of Ang2 from tissue-resident cells enhances vascular permeability by promoting the productions of proinflammatory factors including prostaglandins, VEGF, NFKB, TNF $\alpha$, IL-1 $\beta$, IL-6, and IFN $\gamma$ via the activation of several pathways. Ang2 also recruits immune cells into the injury site(s) and enhances the inflammatory response by stimulating the production of cytokines/chemokines, resulting in fibrosis and tissue injury. ACE2 inactivates Ang2 into mainly Ang-(1-7), and thus the ACE2/Ang-(1-7)/MasR axis is the negative regulatory axis against the ACE/Ang2/AT1R axis in the RAS. Apelin antagonizes the ACE/Ang2/AT1R axis through negative feedback by ACE2 upregulation. In addition, the molecular interaction between AT1R and APJ suppresses the activity of AT1R. The activation of the ACE2/Ang-(1-7)/MasR axis and the apelin/APJ axis has shown an organoprotective effect. ACE, angiotensin-converting enzyme; Ang1, angiotensin 1; Ang2, angiotensin 2; AT1R, angiotensin 1 receptor; CHOP, CCAAT/enhancer-binding protein homologous protein; Cox-2, cyclooxygenase-2; eNOS, endothelial nitric oxide synthase; ERK1/2, extracellular signalregulated kinase; GRP78, glucose-regulated protein 78; HDAC-1, histone deacetylase-1; IFN $\gamma$, interferon gamma; IL-1 $\beta$, interleukin-1 beta; IL-6, interleukin-6; IR-injury, ischemia reperfusion injury; JAK-STAT3, Janus kinase-signal transducer and activator of transcription system; JNK, C-jun-Nterminal kinase; MAPK, mitogen-activated protein kinase; MasR, Mas receptor; MCP-1, reactive oxygen species; MMP, matrix metalloproteinase; NADPH, nicotinamide adenine dinucleotide phosphate; $\mathrm{NFkB}$, nuclear factor kappa-light-chain-enhancer of activated B cells; NO, nitric oxide; PAH, pulmonary artery hypertension; PAI-1, plasminogen activator inhibitor-1; PI3K/Akt, phosphoinositide 3-kinase/protein kinase B; PKC, protein kinase C; ROS, reactive oxygen species; SOD, superoxide dismutase; TGF $\beta$, transforming growth factor-beta; TNF $\alpha$, tumor necrosis factor alpha; VCAM-1, vascular cell adhesion molecule-1; VEGF, vascular endothelial cell growth factor.

(MasR) axis. The function of sACE2 remains unclear. ACE is a close homolog of ACE2 with a $42 \%$ identical sequence in the catalytic domains, which function in an opposite manner to ACE for balancing [162]. ACE2 inactivates Ang2 into mainly Ang-(1-7) and converts Ang1 to Ang-(1-9), whereas ACE inactivates Ang1 into mainly 
Ang2 and converts Ang(1-9) to Ang-(1-7) [162]. Thus, the ACE2/Ang-(1-7)/MasR axis is the negative regulatory axis against the ACE/Ang2/AT1R axis in the RAS.

Ang-(1-7) exerts anti-inflammatory effects via MasR and G proteins. ACE2/Ang-(1-7)/MasR attenuated the local and systemic inflammation reported in various experimental models including sepsis [158], acute lung injury [71], atherosclerosis [189], and chronic kidney disease in mice [31]. Ang-(1-7) also inhibited the release of inflammatory cytokines (IL-6 and tumor necrosis factor alpha $[\mathrm{TNF} \alpha])$ from macrophages that was induced by lipopolysaccharide (LPS) in endotoxemic mice [142, 143]. Ang-(17) also bind to both AT1R and AT2R at high concentrations [163]. In a rheumatoid arthritis model, the ACE2/Ang-(1-7)/AT2R axis also provided an antiinflammatory response by reducing the gene expressions of IL-1 $\beta$ and IL-6 and activating NFkB [157]. Ang-(1-7) inhibited AT1R in a non-competitive manner [120].

In general, the ACE2/Ang-(1-7)/A2R/MasR axis is considered to be a multi-organ protector opposing the ACE/Ang2/AT1R axis. The function of sACE2 remains unclear, but high levels of sACE2 were found in patients with SARS [65], type 1 or type 2 diabetes [44], hypertension [167], heart failure [1], and chronic kidney diseases [1], suggesting that increased sACE2 may act in a protective manner to counteract the adverse effects of Ang2. SARS-CoV-infected wild-type mice had significantly reduced ACE2 expressions in the lung [74] and heart [110].

Pulmonary infectious mice showed an ACE2dependent myocardial injury with a remarkable decrease of ACE2 expression, indicating a key role of ACE2 in mediating SARS-CoV infection in the heart [110]. Further, ace 2 knockout mice exhibited enhanced vascular permeability, increased lung edema, induced neutrophil accumulation in the lung, and worsened lung function [62]. Notably, treatment with recombinant human ACE2 protein (rhACE2) improved the symptoms of acid aspiration- or LPS-induced acute lung injury in mice [62].

\section{Interaction with ACE2 and the Apelin/APJ Axis: Or- gan Protection}

Apelin is another substrate of ACE2 and an endogenous peptide ligand to the $G$ protein-coupled receptor, the APJ [75]. Apelin is expressed predominantly in the endothelium and acts locally via endocrine signaling to activate the APJ, which is expressed on the surface of myocardial cells and endothelial cells [18, 72]. The structure of apelin is similar to that of Ang2 but without binding affinity to AT1R [153]. Apelin-13, a predominant isoform of apelin, antagonizes the ACE/Ang2/AT1R axis through negative feedback by ACE2 upregulation [134]. In addition, the molecular interaction between AT1R and APJ suppresses the activity of AT1R [24]. The apelin/APJ axis reduces vascular tone, decreases blood pressure, regulates fluid homeostasis, improves cardiac contractility [75], and protects against heart [124] and lung injury [35]. In both oleic acid- and LPS-induced ARDS models, treatment with apelin-13 after injury attenuated the lung injury and improved oxygenation [35].

\section{ACE, Ang2, and the AT1R Axis: Proinflammatory Property}

In contrast to the ACE2/Ang-(1-7)/MasR axis, the ACE/Ang2/AT1R axis accelerates the inflammatory response. In this axis, Ang2 is a central regulator of the inflammatory response through specific cell surface receptors (mainly AT1R). As a proinflammatory modulator, Ang2 interacts with both immune cells (neutrophils, mononuclear cells, T cells, and B cells) and tissue-resident cells. The activated Ang2 synthesis from tissue-resident cells enhances vascular permeability by promoting the productions of proinflammatory factors including prostaglandins, vascular endothelial cell growth factor (VEGF) [173], NF $\kappa$ B, TNF $\alpha$, IL-1 $\beta$, IL-6, and interferon gamma $(\mathrm{IFN} \gamma)$ [38].

Ang2 also recruits immune cell infiltration into the injury site(s) and enhances the inflammatory response by stimulating the production of cytokines/chemokines. For example, Ang2 induced the proliferation of splenic lymphocytes via the activation of AT1R on immune cells [106]. In addition, Ang2 upregulates the expression of Toll-like receptor 4 (TLR4), stimulates NFKB signaling, and induces the expressions of CD40, TNF $\alpha$, IL-6, and MMP9 (matrix metallopeptidases) [64, 178].

$\mathrm{TNF} \alpha$ is a key proinflammatory cytokine that acts to cross-link inflammation and the RAS, and its extracellular domain shedding and activation are driven by the ADAM17 on the cell surface [13]. AT1R activation by Ang2 binding phosphonates ADAM17 via the intracellular mitogen-activated protein kinase (p38/MAPK) cellular signaling pathway facilitates the cleavage of ACE2 and tends to the ACE/Ang2/AT1R axis, leading to a positive feedback mechanism in the proinflammatory response [116].

\section{Epithelial and Endothelial Cells: Receptors of SARS- CoV-2}

ACE2 was identified as the binding "receptor" of SARS-CoV and SARS-CoV-2. ACE2 is expressed 
predominantly in the epithelial cells of the lung and intestine [54], suggesting that these organs may be the primary infected sites of SARS-CoV-2. ACE2 is also present in arterial and venous endothelial cells [54]. These distributions of ACE2 are very likely associated with the characteristics of COVID-19: respiratory failure, colitis, microvascular injury, and inflammation.

In COVID-19, the airways and lungs are the main injured organs, and respiratory failure is the leading cause of death [132]. A high expression of ACE2 was identified in alveolar epithelial cells of the lungs of COVID-19 patients [54, 121, 196]. The profiling of the expression of ace 2 RNA in healthy human lung tissue revealed that $83 \%$ of the ACE2expressing cells were alveolar epithelial cells [190]. Multiple ESCRT (endosomal sorting complexes required for transport) machinery genes (including CHMP3, CHMP5, CHMP1A, and VPS37B genes) were shown to be related to virus budding and release [190]. These findings indicate that aside from ACE2, other intracellular mechanisms in alveolar epithelial cells facilitate virus replication in the lungs.

ACE2 is also highly expressed in intestinal epithelial cells $[54,121,196]$, and the intestine may be another potential viral target organ. In an in vitro study using human small intestinal organoids, enterocytes were infected by SARS-CoV or SARS-CoV-2; these small infection clusters had spread throughout the entire organoids at $60 \mathrm{~h}$ post-infection, and the levels of infectious virus particles and viral RNA were significantly increased in both viruses [80]. These data suggested that the intestine might also be an entry site for SARS-CoV-2, and the virus' ability to be transmitted via the mouth/food intake is thus worth investigating.

Severe cases of COVID-19 were frequently characterized by coagulopathy and microvascular injury, leading to organ dysfunction $[151,191]$. The expression of ACE2 in vascular endothelial cells probably contributes to the pathophysiology of microcirculatory pathological changes. The histopathology from three cases of COVID-19 revealed a direct SARS-CoV-2 infection to the endothelial cells leading to diffuse endothelial inflammation [160], which was similar to an earlier report in SARS-CoVinfected patients [184]. The recruitment of immune cells resulted in widespread endothelial dysfunction due to apoptosis [160]. It is thus very likely that microvascular inflammation and dysfunction contribute to the clinical sequelae of multiple organ failure in COVID-19 patients.

\section{THE PATHOLOGY OF THE CYTOKINE STORM}

\section{The Macro-mechanism of the Cytokine Storm in Gen- eral Inflammation}

The cytokine storm begins from a local site of inflammation and then spreads throughout the entire body via an overproduction of inflammatory cytokines and chemokines released by both immune and non-immune cells. These events were directly correlated with organ injury and poor prognosis [101].

Innate immunity was suggested to play a central role in the pathology of this cytokine storm through pattern recognition receptors (PRRs) [23] such as the TLRs, the Nod-like receptors, the RIG-like receptors, and the C-type lectin receptors [68]. Leukocyte activation is mediated by the PRRs, which bind to a wide variety of molecules including pathogen-associated molecular patterns (PAMPs) and the damage-associated molecular patterns (DAMPs) released from infected cells [23, 146, 149].

In the early stage of infectious inflammation, IL-6 is rapidly produced by monocytes/macrophages stimulated by TLRs [136]. The membrane IL-6 receptor (mIL-6R) is expressed only in some immune cells, but the soluble IL-6 receptor (sIL-6R) is widely present in both immune and non-immune cells [131]. IL-6 induces various actions to activate glycoprotein 130 (gp130, which is expressed in most cells) by the IL-6 receptor complex (the details of the mechanism of action are described below) [98]. IL-6 is an essential cytokine for maintaining homeostasis in the body, and when stress is removed, the synthesis of IL- 6 ceases but excess IL-6 production causes chronic inflammatory diseases and a severe systemic inflammatory response, i.e., the cytokine storm [101].

\section{The Micro-mechanism of the Cytokine Storm in COVID-19}

SARS-CoV-2 binds directly to the host cells' surface ACE2. The virus cleavage in the host endosome activates NFKB via TLRs and the MyD88 (myeloid differentiation primary response 88 ) pathway [168], which stimulates IL6 protein transcription in the host immune cells. Once ACE2 is occupied by the virus, free Ang2 accumulates in the plasma due to a lack of degradation by ACE2. The mIL-6R exists only on immune cells such as $\mathrm{T}$ cells, monocytes, macrophages, activated $\mathrm{B}$ cells, neutrophils, and osteoclasts [131], where the classic IL-6 signaling occurs following the anti-inflammatory bioreaction. After the A2R activation by excess Ang2 binding, sIL-6R is derived from the shedding of mIL-6R by ADAM10 and 
Iwasaki, Saito, Zhao, Sakamoto, Hirota, and Ma

ADAM17 [40]. In contrast, gp130 is expressed widely as another type of IL-6R on the surface of non-immune cells, and it can be activated by a trans-signaling of IL- 6 and sIL6R [130] or the trans-presentation of IL-6/mIL-6R complex on another immune cell [56] (Fig. 2).

The IL-6 trans-signaling leads to an immense effect due to the widespread presence of gp130 on both immune and non-immune cells and also due to the suppression of intracellular negative feedback by SOCS (suppressor of cytokine signaling) 3 via the Janus kinase-signal transducers and activators of transcription (JAK-STAT3) pathway in the immune cells [105]. When the IL-6/IL-6R/ gp130 complex is formed, the IL-6 signal is transmitted via three intracellular signaling pathways (i.e., the JAKSTAT [especially STAT3], RAS/MAPK, and PI3K/Akt pathways), producing proinflammatory cytokines such as NF $\kappa B$, VEGF, MMP9, and IL-6. In addition, non-immune cells such as endothelial cells, smooth muscle cells, and fibroblasts are activated by NFKB and STAT3 and then release IL-7, which stimulates CD4-positive cells to release IL-6 and IL-17a, resulting in positive feedback to the nonimmune cells in the IL-6 amplification cycle [103]. This IL-6 hyperactivation cycle induces the systemic status recognized clinically as the cytokine release syndrome, or cytokine storm.

\section{Organ Injury by the Cytokine Storm}

The lungs are the organ that is most vulnerable to the above-described cytokine storm, and ARDS is a common, fatal condition that follows a cytokine storm in the alveolar environment and systemic circulation, induced by SARS$\mathrm{CoV}$, MERS-CoV, and severe influenza as well as SARSCoV-2 [159, 171]. An acute mononuclear/neutrophilic inflammatory response induced ARDS, followed by a chronic fibroproliferative phase with progressive collagen deposition in the lung. This may be explained by the findings that pulmonary endothelial cells $[155,156]$ and epithelial cells [78] have critical roles in both the promotion of cytokine amplification and the innate immune cell recruitment by cytokine storm during viral infection.

After N1H1 influenza infection, pulmonary endothelial cells secreted cytokines (IL-6, IFN $\alpha$, IFN $\gamma$, and $\mathrm{TNF} \alpha$ ) and chemokines (CCL-2) and recruited innate immune cells (macrophages and natural killer cells) but not lymphocytes [155]. Due to the injurious effects of these proinflammatory cytokines and chemokines, vascular permeability increases, and fluid and blood cells leak into the alveoli, resulting in dyspnea and even respiratory failure.

\section{THE MECHANISMS UNDERLYING SARS-COV-2 INFECTION}

\section{SARS-CoV and SARS-CoV-2}

SARS-CoV-2 is a single-stranded RNA virus with a high similarity to SARS-CoV, sharing $80 \%$ genome sequence identity $[49,164,174,187]$ and $90 \%$ sequence identity in their N-terminals of the receptor-binding domain and similarity to other essential enzymes [109, 174]. Both viruses have a nucleocapsid inside with two types of spike proteins ( $\mathrm{S} 1$ and $\mathrm{S} 2$ ) on the viral surface. S1 is involved in the attachment of the virus to host cells and is considered to be a target of neutralizing antibodies [43]. S2 is involved in cell membrane fusion [34] and is a potential target of fusion inhibitors. Based on clinical analyses of the basic reproductive number (R0), SARS-CoV-2 (R0 2.2$2.7[139,177])$ appears to have infectivity that is comparable to that of SARS-CoV (R0 1.5-3.4 [22, 86, 128]). In addition, the latest genome analyses demonstrated that SARS-CoV-2 has its own sequence for furin cleavage $[28,164]$.

\section{ACE2: a Functional "Receptor" of SARS-CoV-2}

SARS-CoV-2 can enter host cells via two mechanisms: "endosome attachment fusion" and "direct-attachment fusion" (Fig. 3). After virus attachment, the S1 protein of SARS-CoV-2 binds to ACE2 on the host cell membrane to enter the cell [83] after the activation of S1 protein ("cleavage") by host proteinase "priming." The viral S1 protein priming depends on transmembrane protease serine 2 (TMPRSS2) and other host proteases including the endosomal cysteine proteases cathepsins $\mathrm{B}$ and $\mathrm{L}$ (CatB/L) [60]. TMPRSS2 is a co-factor of ACE2 and is coexpressed in type II pneumocytes with ACE2 [9, 45, 145, 195], bronchial transient secretory cells [88], and nasal secretory cells [195], which are known as enriched sources of SARS-CoV-2 to be detected clinically [193].

The co-expression of ACE2 and TMPRSS2 was reported in type 1 pneumocytes [195], alveolar macrophages [9, 192], lymphocytes [9], smooth muscle cells and enterocytes in the gastrointestinal tract $[9,195]$, vessel smooth muscle cells [9], cardiomyocytes [9, 192], hepatocytes [169], kidney cells [87], proximal tubule cells [114], and neurons [112], all of which are in line with the common clinical symptoms of COVID-19 [15, 19, 61, 151, 166, 183, 191, 197]. Single-cell RNA profiling revealed that male gender, advanced age, and smoking habit can increase the co-expression of ACE2 and TMPRESS2 


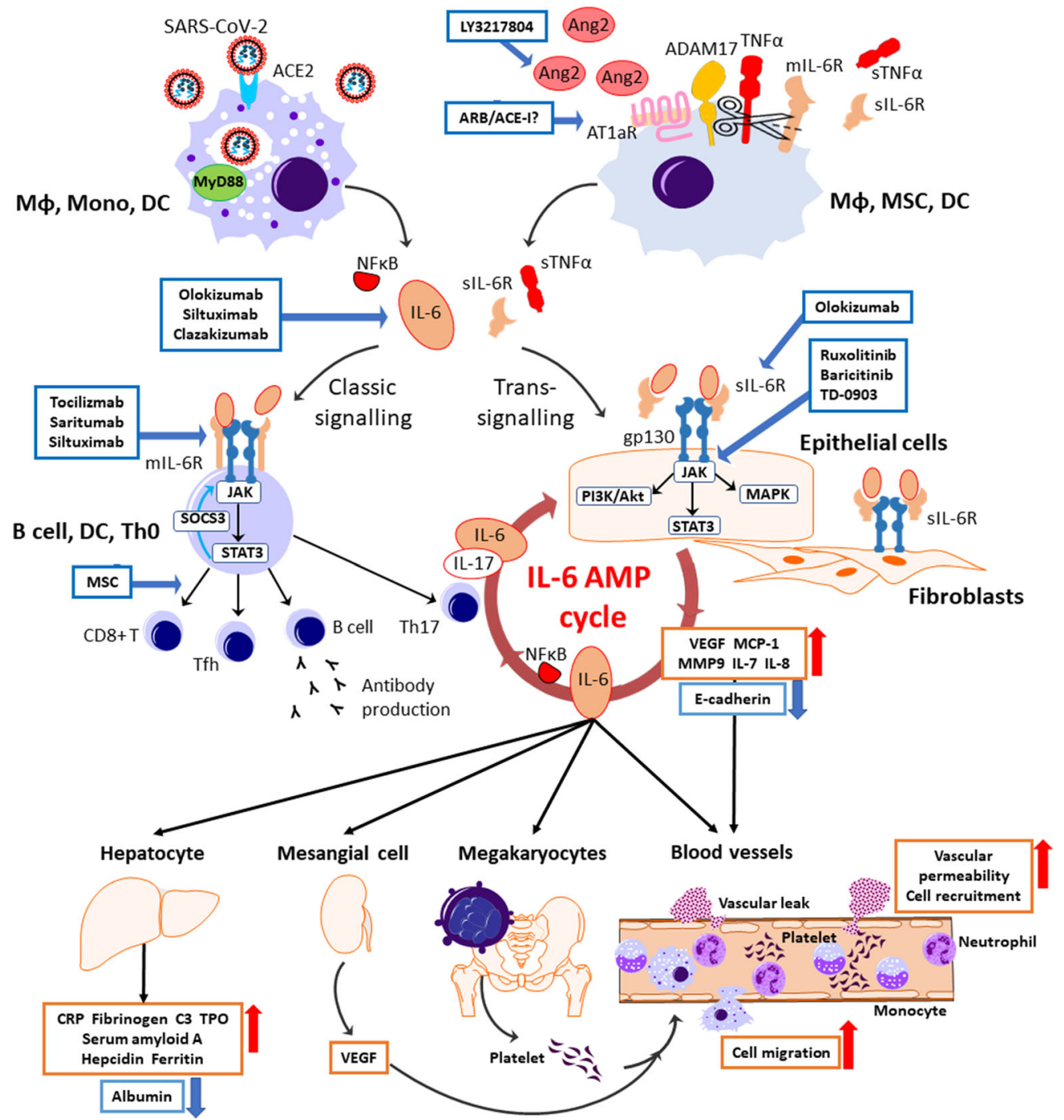

Fig. 2. The therapeutics under clinical trials targeting the cytokine storm in SARS-CoV-2 infection. SARS-CoV-2 attaches to ACE2 and enters the host cell. Viral components are recognized by the MyD88 pathway in the endosome, leading to the releases of IL-6 and NFKB from immune cells including macrophages, monocytes, and dendrites. The possession of ACE2 by the virus causes the accumulation of Ang2 in the extracellular space. After the activation of AT1aR by excess Ang2 binding, sIL-6R is produced from the shedding of mIL-6R by ADAM10 and ADAM17 with a release of sTNF $\alpha$ from macrophages, mesenchymal stem cells (MSCs), and dendritic cells (DCs). IL-6 binds to the target cells via two signaling pathways: classic signaling only for specific immune cells, and trans-signaling for any cells including the immune cells, epithelial cells, and fibroblasts. In the classic signaling pathway, IL-6 binds to mIL-6R on the immune cells and activates B cells or differentiates CD8+ T cells, helper T cells, and Th17 cells, which triggers an anti-inflammation response. There is a negative feedback mechanism to the JAK-STAT pathway by SOCS3. In trans-signaling, IL-6/sIL-6R complex can bind to gp130 following the release of proinflammatory cytokines and IL-6 via three intracellular pathways without SOCS3 negative feedback. Since gp130 is highly expressed on almost all types of cells including the immune cells, sIL-6R shedding by ADAM17 provokes a surge of IL-surge mostly via trans-signaling. IL-6 stimulates the production of IL- 6 and IL-17 $\alpha$ from Th17 cells, resulting an IL-6 burst in its amplification cycle. The proinflammation cytokines increase vascular permeability and cell migration, enhancing the inflammation response. IL- 6 also stimulates megakaryocytes, renal mesangial cells, and hepatocytes with the subsequent inflammatory response and vital organ injury. ARB/ACE-I, angiotensin receptor blocker/ACE2 inhibitor; AT1aR, angiotensin receptor subtype 1a; C3, complement component 3; E-cadherin, epithelial cadherin; gp130, glycoprotein 130; IL, interleukin; JAK, Janus kinase; MAPK, mitogenactivated protein kinase; MCP-1, monocyte chemoattractant protein 1; mIL-6R, membrane interleukin 6 receptor; MMP9, matrix metallopeptidase 9; MyD88, myeloid differentiation primary response 88; NFkB, nuclear factor kappa-light-chain-enhancer of activated B cells; NFkB, nuclear factor kappa B; PI3K/Akt, phosphoinositide-3-kinase/protein Kinase B; SARS-CoV-2, severe acute respiratory syndrome coronavirus 2; sIL-6R, soluble interleukin 6 receptor; SOCS3, the suppressor of cytokine signaling-3; STAT3, signal transducers and activators of transcription; sTNF $\alpha$, soluble tumor necrosis factor alpha; Tfh, follicular helper T cell; Th0, naive T cell; Th17, T helper 17 cell; TMPRSS2, transmembrane protease serine 2; TNF $\alpha$, tumor necrosis factor alpha; TPO, thrombopoietin; VEGF, vascular endothelial growth factor. 


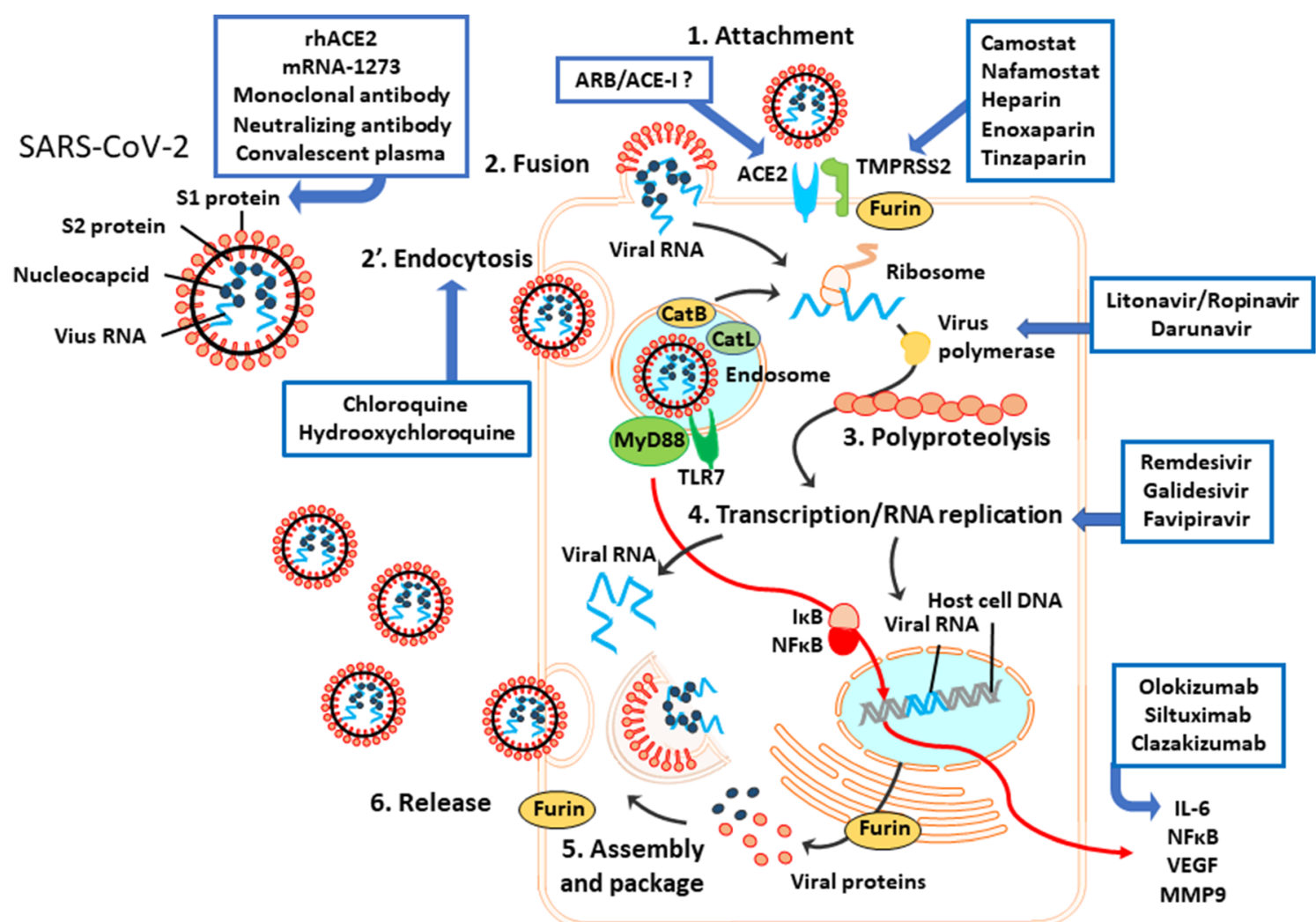

Fig. 3. The putative mechanisms of SARS-CoV-2 infection. SARS-CoV-2 has two surface proteins and single-strand RNA with nucleocapsid proteins. S1 protein binds to the host ACE2 by cleavage with TMPRSS2 and furin. After this attachment, the virus enters the host cell via fusion or endocytosis. In the endosome, cathepsins $\mathrm{B}$ and $\mathrm{L}$ activate the $\mathrm{S} 2$ protein of the virus for membrane fusion. The virus components are recognized by TLR7, leading to the release of proinflammation cytokines (IL-6, NFkB, VEGF, and MMP9) via the MyD88 pathway in immune cells such as macrophages, monocytes, and dendritic cells. Once the virus RNA is released in the host cytoplasm, the virus polypeptide chain with ribosome translation is processed in the replication/transcription complex by virus RNA polymerase. Replicated virus RNA and proteins are assembled and packed with the host membrane in the host cytoplasm. Virus is released from the cell by exocytosis or the host cell's burst. ARB/ACE-I, angiotensin receptor blocker/ACE inhibitor; Cat L, cathepsin L; CatB, cathepsin B; IкB, inhibitory proteins of $\mathrm{kB}$ family; MMP9, matrix metallopeptidase 9; MyD88, myeloid differentiation primary response 88; NFkB, nuclear factor kappalight-chain-enhancer of activated B cells; rhACE2, recombinant human ACE2 protein; TLR7, Toll-like receptor 7; TMPRSS2, transmembrane protease serine 2 .

[104], and these are known as clinical risk factors for severe COVID-19 [61, 63, 151, 166, 175, 191, 194].

Genome analyses showed that SARS-CoV-2 has a unique sequence for a furin cleavage site [28, 164], which may determine the viral affinity to host cells $[70,165]$. Furin, a peptidase that is also known as PACE (paired basic amino acid cleaving enzyme), may also be involved in this process. Recent research revealed that furin cleaved the $\mathrm{S} 1 /$ S2 proteins of SARS-CoV-2 and was essential for virus fusion with the host membrane [59]. It has been estimated that compared to SARS-CoV, SARS-CoV-2 has 10-20fold higher affinity to host membrane ACE2 [174], possibly due to its own FURIN sequence [34]. Furin is highly expressed in lung tissue $[4,28]$ and it was observed that
$43 \%$ of furin + bronchial transient secretory cells were coexpressed with TMPRESS2 [88]. The triple expression of ACE2, TMPRSS2, and furin was detected in lung macrophages, kidney, adrenal stromal cells, intestine endocytes [192], and nasal epithelial cells [176], strongly suggesting that those organs are susceptible to SARS-CoV-2 infection.

\section{SARS-CoV-2 Entry Associated with Host ACE2, TMPRSS2, and Furin}

Once the viral S1 protein attaches to the host cell membrane's ACE2, the virus enters the cell by host endocytosis, which is dependent on the host cell's clathrin [20, $60]$. Viral S2 protein is activated by the proteolysis 
cleavage with the host cell's CatB/L in endosomes [7, 99, 140] or with TMPRSS2, CatB/L, and furin in the extracellular space [60], inducing viral envelope fusion to the host membrane and the release of the virus component.

CatB was reported to be co-expressed in $>70$ $90 \%$ of human ACE2+ nasal secretory cells [144]. At the same time, the virus cleavage via TLR7 and the MyD88 pathway activates the production of NFKB, which stimulates IL-6 protein transcription in the host immune cells [168]. The replicationtranscription complex processes the viral genome replication in the cytoplasm, and the transcription of viral proteins is processed in the host nucleus separately. The replicated viral RNA and protein are then assembled in the host cytoplasm, and the virus envelope is modified by the host components. Replicated virus buds from the host cells by exocytosis or the bursting of the host cell.

\section{SARS-CoV-2 Infection Induces a Cytokine Storm with an Interaction with the RAS}

Simultaneously, the ACE2 possession by SARSCoV-2 induces accumulations of sACE2 in the blood and urine [12], with the subsequent cytokine storm including the release of IL-6 from the host macrophage [14, 147] as described above. These events are closely linked to the worsening of lymphocytopenia [30], hypercoagulation [97], higher mortality [175], and poor clinical outcomes $[10,11,61,122]$. It was shown that in SARS-CoV infection, the activation of A2R (mostly AT1aR) by Ang2 binding stimulates ADAM17 to promote the shedding of ACE2 into the extracellular space (which increases the uptake of SARS-CoV into cells [51, 52]) and leads to the direct cleavage of SARS-CoV S protein and the induction of the release of TNF $\alpha /$ IL-6 [58]. In addition, AT1aR and ADAM17 are co-expressed on various cell types such as endothelial cells [170] and vascular smooth muscle cells [108], which were reported to be involved in pathological lesions in COVID-19 patients [15, 61, 67, 166, 179].

In summary, SARS-CoV-2 entry is facilitated by the host cells' ACE2, TMPRSS2, and furin, inducing the activation of $\mathrm{A} 2 \mathrm{R}$ and the cytokine storm starting with IL-6 release. Insights into the co-expression of ACE2, TMPRSS2, and furin may help to identify the organs that are vulnerable to SARS-CoV-2 infection and may contribute to the development of potential therapeutic strategies.

\section{MULTI-ORGAN DYSFUNCTION/FAILURE}

\section{Respiratory Failure/ARDS}

As noted above, the lungs are the organ most vulnerable to SARS-CoV-2, and importantly, respiratory failure associated with ARDS is the leading cause of death in individuals with COVID-19, contributing to $86 \%$ of the deaths [132]. In the severe or critical cases in intensive care units (ICUs), 53-95\% of the patients developed ARDS [2, 183, 197]. Among those, $2-11 \%$ of the patients with ARDS required extracorporeal membrane oxygenation support, and the survival rate of those patients was quite low $[61,166,183,191]$. The onset time of ARDS related to COVID-19 was 8-12 days [61, 166, 191], which is not consistent with the ARDS Berlin criteria [37], but histological examinations revealed that the pathophysiological features are similar to the common ARDS [19].

\section{Myocardial Injury}

Numerous studies revealed that acute cardiac injury was also a common complication of COVID-19 [2, 19, 50, $61,138,139,166,183,191,197]$ and was associated with poor outcomes among severe COVID-19 patients [50, 138, 139]. It has been proposed that this might be due to the development of heart failure $[138,191]$ and lethal arrhythmias [50]. Acute cardiac injury is defined as the elevation of cardiac troponin (high-sensitivity troponin I [hsTnI]) and/or troponin $\mathrm{T}$ ([TnT) to >99th percentile alone, or a composite of troponin elevation and ECG or echocardiographic abnormalities $[2,19,50,61,138$, 139, 166, 183, 191, 197].

Two cohort studies showed that $19.7-27.8 \%$ of hospitalized COVID-19 patients exhibited myocardial injury as indicated by elevated hsTnI [139] and TnT [50]. The mortality rate of COVID-19 patients with cardiac injury was significantly higher than that of the patients without cardiac injury $(51.2 \%$ vs. $4.5 \%, p<0.001)$, and cardiac injury was an independent predictor of in-hospital mortality as well as ARDS [139]. The troponin level of COVID19 patients was positively correlated with the level of NTProBNP (N-terminal-pro hormone B-type natriuretic peptide) $1[50,139]$, indicating that cardiac injury is associated with poor clinical outcomes among COVID-19 patients.

The mechanisms underlying cardiac injury in the context of COVID-19 remain to be investigated, but may be due to a direct injury from SARS-CoV-2 infection and then exacerbation by inflammatory responses. The expression of ACE2 on the myocardium [50] and vascular endothelial cells [54] provides a theoretical mechanism of the 
direct injury by SARS-COV-2 to the heart, with resultant myocarditis. Indeed, the viral RNA was detected in heart autopsies [172]. In addition, excess inflammation causes endothelial dysfunction and increases the prothrombotic activity of the blood, both of which may contribute to the formation of an occlusive thrombus, leading to acute coronary syndrome and myocardial injury.

\section{Acute Kidney Injury}

The prevalence of acute kidney injury (AKI) varied depending on the severity of COVID-19 [2, 21, 48, 139, 183, 191, 197]. Two large observational studies showed that the prevalence of AKI was relatively low $(0.5-5 \%)$ in hospitalized COVID-19 patients [21, 48]. Kidney functional abnormalities including proteinuria (43.9\%) and hematuria $(26.7 \%)$ were observed in many COVID-19 patients, and, importantly, the kidney abnormalities were independent predictors of in-hospital death: proteinuria of any degree, hematuria of any degree, elevated baseline blood urea nitrogen, serum creatinine, peak serum creatinine $>$ $133 \mu \mathrm{mol} / \mathrm{L}$, and AKI > stage 2 [21].

The mechanisms that underlie kidney injury/ abnormality have been hypothesized to include both direct cytotoxic effects of SARS-CoV-2 itself and cytokinemediated damage [21]. ACE2 was shown to express in glomerular parietal epithelial cells and epithelial basal cells in the kidneys and in kidney proximal tubules [121, 196]. SARS-CoV-2 enters the host cells via the binding of ACE2 on epithelial cells. Indeed, an evaluation of 12 autopsy cases revealed that six patients had viremia, and viral RNA was also detected in kidney tissues at concentrations exceeding viremia [172].

These data suggest that SARS-CoV-2 spreads through the bloodstream and directly injures the kidneys. The cytokine storm (a hyper-inflammatory status) might exert indirect effects on renal abnormalities such as hypoxia secondary due to respiratory failure, septic and cardiogenic shock, and rhabdomyolysis, all of which were reported in patients with severe influenza viral infection [76].

\section{Liver Injury}

Several cohort studies reported that liver injury occurred in COVID-19 patients, and the liver injuries were described mainly as an increase in the level of alanine aminotransferase (ALT), aspartate aminotransferase (AST), or total bilirubin accompanied by slightly decreased albumin $[2,19,50,61,175,183,191,197]$. Patient series with severe COVID-19 or non-survivors were more likely to have a higher prevalence of liver injury compared to mild cases and survivors [19, 61, 175, 191, 197].

In a retrospective study, liver injury was detected in $35.4 \%$ of non-ICU patients with COVID-19 [61]. Male patients and patients with high levels of white blood cells, neutrophils, and CRP and a greater extent of pulmonary lesions on computed tomography were more likely to have liver injury [61]. The expression of ACE2 was observed on endothelial cells of the liver and cholangiocytes as well as other vital organs [54, 121]. The study of 12 autopsy cases showed high SARS-CoV-2 RNA titers in the liver [172]. The liver biopsy of a COVID-19 patient revealed microvesicular steatosis and lobular and portal activity, suggesting that the injury was caused by either SARS-CoV-2 infection or drug-induced injury [19]. As cholangiocytes play pivotal roles in the initiation and regulation of immune responses and liver regeneration [3], it is possible that liver injury and bile duct injury are caused directly by viral infection.

\section{The Gastrointestinal Injury/Gut-Lung Axis}

Digestive manifestations including lack of appetite, nausea, vomiting, diarrhea, abdominal pain, and gastrointestinal hemorrhage have been documented in patients with SARS-CoV-2 infection [19, 48, 66, 113, 166, 183, 188, 197]. COVID-19 patients with digestive manifestations were significantly more likely to require intensive care admission and to have ARDS compared to patients without gastrointestinal symptoms (6.8\% vs. $2.1 \%, p=0.034$, and $6.8 \%$ vs. $2.1 \%, p=0.034$, respectively) [66], indicating an association between the presence of digestive symptoms and disease severity. The gut microbiota have been shown to affect lung health through an important crosstalk between the gut microbiota and the lungs, which is called the "gut-lung axis" [16]. The gut-lung axis is bidirectional, and microbial metabolites affect the lungs via the blood stream while inflammation in the lungs also affects the gut flora [16]. This raises the interesting possibility that SARSCoV-2 may also affect the gut microbiota. Viral RNA has been detected in stool samples of COVID-19 patients $[148,180]$. The SARS-CoV-2 itself may cause disorders of the intestinal flora, which may result in digestive symptoms and deterioration of patients with ARDS.

\section{Neurological Injuries}

Neurological injuries including central nervous system (CNS) symptoms, peripheral nervous system (PNS) symptoms, and skeletal muscle injury symptoms have been observed in patients with mild to severe COVID-19 [8, 19, 
$81,92,102,119,186]$. Two cohort studies [19, 81] reported high prevalence of olfactory (68-86\%) and gustatory (71-88\%) dysfunctions in COVID-19-positive patients, and olfactory dysfunction appeared before the other symptoms in $11.8 \%$ of the cases [19]. These two chemosensory dysfunctions were independently and strongly associated with COVID-19 positivity [19] and should be considered to be early signs of the disease.

A retrospective analysis of neurological manifestations of COVID-19 demonstrated that of 214 patients, $36.4 \%$ of the hospitalized patients had neurologic manifestations: CNS (24.8\%), PNS (8.9\%), and skeletal muscle (10.7\%) injury [94]. In the groups of patients with CNS manifestations, neurologic disorders were more common in the severe patients compared to the non-severe patients; the disorders included acute cerebrovascular diseases (5.7\% vs. $0.8 \%)$, impaired consciousness (14.8\% vs. $2.4 \%)$, and neural skeletal muscle injury $(19.3 \%$ vs. 4.8\%) [92]. More severe neurological manifestations were reported in a few case reports $[8,102,119]$; for example, a 24-year-old male experienced a coma, seizures, and neck stiffness [102]. SARS-CoV-2 RNA was detected in his cerebrospinal fluid (CSF), and subsequent magnetic resonance imaging indicated right lateral ventriculitis and encephalitis mainly at the right mesial lobe and hippocampus, where SARS-CoV2-associated meningitis/encephalitis was diagnosed [102]. The mechanism may be a direct invasion of SARS-CoV-2, similar to SARS virus [181].

Brain tissues highly express ACE2 [138], and SARSCoV-2 RNA was found in the CSF of the abovementioned COVID-19 patient [102] and in the patient's brain autopsy [172]. As with other respiratory viruses, SARS-CoV-2 may enter the CNS through a hematogenous or retrograde neural route [92]. The latter route is supported by the finding that COVID-19 patients have a high prevalence of olfactory dysfunction. The results of the above-cited retrospective analysis suggested that the observed neurological symptoms may likely be associated with worse prognosis in COVID-19 [92].

A tissue profiling analysis showed that ACE2 is strongly expressed in the respiratory control center, the ventrolateral medulla, and the nucleus of the tractus solitarius $[33,111]$. Other coronaviruses with structures that are similar to that of SARS-CoV-2 have been reported to cause the apoptosis of neurocytes in the respiratory center to a degree that is high enough to drive the lethal nervousrespiratory malfunction $[32,85,93,107]$. Thus, the respiratory failure in COVID-19 might be caused in part by the invasion of SARS-CoV-2 to the neurons of the cardiorespiratory center in the ventrolateral medulla. The findings described above may explain why, in some COVID-19 patients, their respiratory function can be deteriorated very quickly and patients die suddenly.

\section{Microvascular Injuries}

Hospitalized patients with severe COVID-19 had a prolonged prothrombin time (PT), a prolonged activated partial thromboplastin time (APTT), and elevated D-dimer [73, 127, 150, 151, 191]. Among those patients, some developed disseminated intravascular coagulopathy (DIC) $[19,150,151]$. A higher D-dimer level or higher sepsisinduced coagulopathy $(S I C)$ score was associated with the severity of or death from COVID-19 [19, 29, 150, 191]. The clinical picture of coagulopathy associated with COVID-19 appears to be prothrombotic, and a high prevalence $(25-42 \%)$ of venous thromboembolism (VTE), including deep vein thrombosis (DVT) and pulmonary embolism (PE), was observed in ICU patients with severe COVID-19 [29, 57, 73].

A multicenter prospective cohort study revealed that elevated D-dimer and fibrinogen levels at admission were present in 95\% of COVID-19 patients in the ICU, and among 150 patients, $64(42 \%)$ developed VTE including 25 cases of PE [57]. In addition, the study of 12 autopsy cases revealed DVT in seven of the 12 patients $(58 \%)$, and PE was the direct cause of death in four patients [172]. It could be hypothesized that multi-organ injury is a result of microthrombus formation in the vital organs due to the prothrombotic state of COVID-19. It is uncertain whether the observed coagulopathy is caused by the virus or is secondary due to a cytokine storm. Early interventions such as anti-coagulant administration might be beneficial in severe COVID-19 patients [150], but this warrants further study.

\section{Kawasaki-Like Disease-Related SARS-CoV-2 Infection}

According to cohort studies, most children who are infected with SARS-CoV-2 appear to have mild clinical symptoms and better prognoses compared to infected adults [48, 137]. However, shortly after the spread of SARS-CoV-2 infection was detected, the increased incidence of Kawasaki disease or Kawasaki-like disease was documented in western countries $[55,129,161]$. Eight of the ten pediatric patients identified had an antibody against SARS-CoV-2 [161]. Children diagnosed after the SARS-CoV-2 epidemic was identified were older and had a higher rate of cardiac dysfunction, and they showed features of macrophage activation syndrome (MAS), called 
"Kawasaki-like disease" [161]. The MAS criteria are validated for systemic juvenile idiopathic arthritis, but they are commonly used for other systemic auto-inflammatory diseases such as Kawasaki disease [41]. MAS is a form of cytokine storm in which clinical features (i.e., high fever, lymphopenia, and high levels of transaminase, lactate dehydrogenase, D-dimer, and ferritin) are shared with severe COVID-19. Patients diagnosed with Kawasaki-like disease after the beginning of the SARSCoV-2 epidemic showed a severe phenotype and required early interventions including steroid treatment [161] and intravenous immunoglobulin [55].

\section{Multi-organ Dysfunction/Injury and Outcomes}

Clinical observational studies revealed that the organ injuries discussed above are associated with death due to COVID-19. The reported prevalence of the injuries among patients with COVID-19 include ARDS (81-100\%) [19, 183, 191, 197], cardiac injury (28-77\%) [19, 183, 191, 197], AKI (38-50\%) [183, 191, 197], liver dysfunction $(25-28 \%)$ [183, 197], coagulopathy $(50-71 \%)$ [151, 191], hypoxic encephalopathy $(20 \%)$ [19], and gastrointestinal hemorrhage $(6-8 \%)$ [183, 197]. The incidence of organ injury in the non-surviving patients was significantly higher than that in the surviving patients $[19,151,183$, 191, 197]. These organ injuries were independent predictors of death from COVID-19 [21, 139] (Fig. 4).

\section{FUTURE PERSPECTIVES ON THERAPEUTICS AND ONGOING STUDIES}

\section{The Evidence About COVID-19 Treatment}

As of the end of May 2020, almost 500 interventional studies were ongoing or planned across the world. There is only one double-blinded, full-powered randomized trial (RCT) about COVDI-19 treatment that has been completed and published: four clinical trials of remdesivir, and one controlled prospective study and four controlled clinical trials of chloroquine. The US Food and Drug Administration (FDA) has not approved any drugs for COVID-19 treatment as of this writing. There are also no US National Institutes of Health (NIH) treatment guidelines, due to the insufficient amount of clinical data that are necessary to determine a drug's efficacy and safety.

Remdesivir, a viral RNA polymerase inhibitor, has been reported to inhibit SARS-CoV-2 polyproteolysis in vitro [191] and was administered as compassionate use in a case series [47] with clinical improvements. Four clinical trials of remdesivir were completed or the trials' preliminary results were reported. The only double-blinded full-powered RCT to date is the Adaptive COVID-19 Treatment Trial (ACTT trial, $n=1063$ patients, NCT04280705), which has shown that remdesivir accelerated recovery compared to the placebo (11 days $v s .15$ days, $p<0.001,[6])$ with a tentative finding of a lower mortality rate $(8.0 \%$ vs. $11.6 \%, p=0.059$, press release). The subgroup analysis and the further outcome analysis with a larger patient number will be published eventually.

A comparison of remdesivir treatment $(n=155)$ and placebo $(n=78)$ for COVID-19 patients in China [21] (NCT04257656) was initiated for patients who exhibited severe disease within 14 days after symptom onset, but this double-blind placebo-controlled RCT was terminated early because there was no difference in clinical improvement between the remdesivir and placebo: hazard ratio (HR) 1.23, $95 \%$ confidence interval $(\mathrm{CI}), 0.87-1.75$. Two SIMPLE trials conducted by the biopharmaceutical company Gilead (severe patients in NCT04292899 and moderate patients in NCT04292730) compared the clinical outcomes on day 14 between 5-day $(n=200)$ and 10-day $(n=197)$ remdesivir treatment starting within 4 days after the diagnosis among moderate or severe COVID-19 patients. The primary results showed no significant difference in outcomes or adverse events overall [46]. These trials are planning to recruit 6000 severe patients and 1600 moderate patients to be completed.

Lopinavir-ritonavir (L/R) is a human immunodeficiency virus (HIV) protease inhibitor. There is currently no large RCT testing the benefit and safety of L/R for COVID-19 patients. The latest open-label RCT with 199 severe patients revealed that compared to the control group, treatment with lopinavir (400 mg) and ritonavir $(100 \mathrm{mg})$ did not boost the patients' symptom recovery (HR $1.24,95 \%$ CI $0.90-1.72$ ) or their outcomes (mortality at day 28, L/R $19.2 \%$ vs. control $25 \%, 95 \%$ CI $-17.3-5.7)$ [17].

\section{Ongoing Clinical Trials Targeting ACE2}

\section{Endocytosis Inhibition: Chloroquine}

Chloroquine (CQ) is a classic antimalarial and a potential antiviral agent [135]. In vitro, chloroquine effectively inhibited SARS-CoV-2 entry into cells $(\mathrm{EC} 50=1.13 \mu \mathrm{M})[191]$, possibly by binding to the host respiratory cells, which would inhibit the attachment of the virus S1 protein to the host ACE2 on the host cells [36]. Five placebo-controlled clinical studies have described the outcomes of chloroquine treatment for COVID-19 patients. 


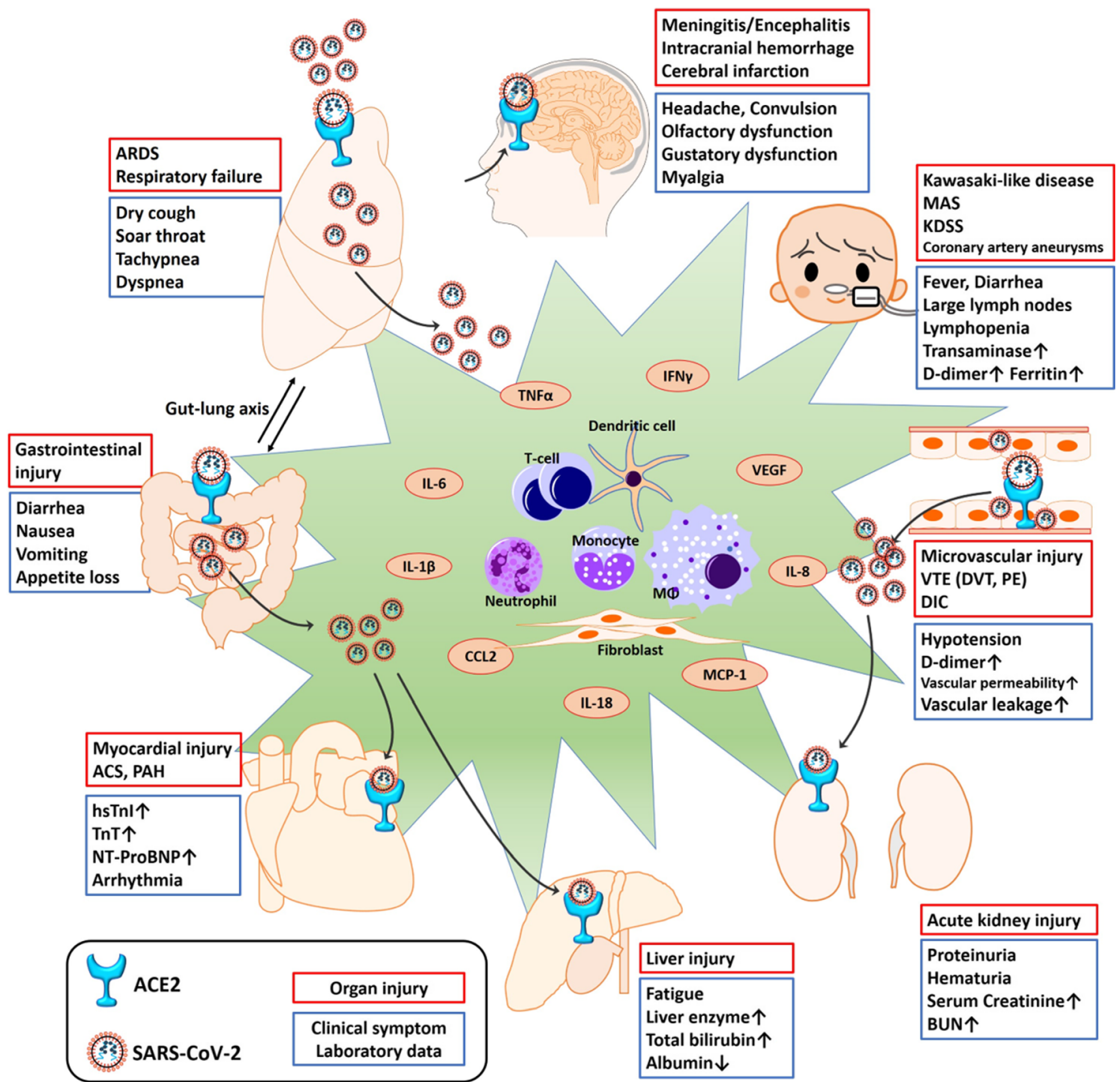

Fig. 4. Clinical manifestations induced by SARS-CoV-2 infection. Organ dysfunction includes both direct cytotoxic effects of SARS-CoV-2 itself and cytokine-mediated damage. ACE2 was observed to be expressed in several types of tissue (including vessel endothelial and smooth muscle) and vital organs (lung, heart, intestine, brain, kidney, liver, etc.). The SARS-CoV-2 enters the host cells by binding to ACE2 and then directly damages the target organ. SARS-CoV-2 infection induces a release of proinflammatory cytokines (TNF $\alpha$, IL-6 and others), resulting in injury to the target organ. ACS, acute coronary syndrome; ARDS, acute respiratory distress syndrome; BUN, blood urea nitrogen; CCL2, chemokine ligand 2; DIC, disseminated intravascular coagulation; DVT, deep vein thrombosis; hsTnI, high sensitive troponin I; IFN $\gamma$, interferon gamma; KDSS, Kawasaki disease shock syndrome; MAS, macrophage activation syndrome; MCP-1, monocyte chemoattractant protein 1; NT-ProBNP, N-terminal-pro hormone B-type natriuretic peptide; PAH, pulmonary artery hypertension; PE, pulmonary embolism; TnT, troponin T; VTE, venous thromboembolism.

A recent large placebo-controlled RCT with 14,888 COVID-19 patients indicated that hydroxychloroquine (HCQ) or CQ or in combination with a macrolide was related to worse in-hospital mortality [96]. In that RCT, 1868 patients received CQ alone, 3783 patients received CQ with a macrolide, 3016 patients received HCQ alone, and 6221 patients received HCQ with a macrolide; 81,144 patients served as the control group. The in-hospital mortality rates were higher in each treated group compared to the control after the cross-matching of the confounding factors: in-hospital mortality, control 9.3\%; HCQ $18.0 \%$ (HR 1.335, 95\% CI 1.223-1.457); HCQ + macrolide 
23.8\% (HR 1.447, 95\% CI 1.368-1.531); CQ 16.4\% (HR $1.365,95 \%$ CI $1.218-1.531$ ); and CQ + macrolide $22.2 \%$ (HR 1.368, 95\% CI 1.273-1.469). Moreover, each treated group had ventricular arrhythmia during hospitalization compared to the control [96].

An interventional study of 181 COVID-19 patients ( 84 received CQ $600 \mathrm{mg} /$ day vs. 97 without chloroquine) showed no improvement of symptoms, mortality, or transfer to the ICU at day 7 after hospitalization [90]. Another open-label RCT of 150 patients treated with HCQ showed no significant improvement in virus conversion (HCQ $v s$. control: 8 days $v s .7$ days, HR $0.85,95 \%$ CI $0.58-1.2 ; p=$ 0.34 ) or the symptom recovery time (HCQ vs. control: 19 days vs. 21 days, HR 1.01, 95\% CI 0.59-1.74; $p=$ 0.97 ) up to day 28 [152]. A small study of 62 patients in China indicated that CQ $400 \mathrm{mg} /$ day might improve pneumonia in mild-moderate COVID-19, but a significant difference was not observed (ChiCTR2000029559) [172]. Another small controlled prospective study showed that compared to the control group $(n=20)$, HCQ $(600 \mathrm{mg} /$ day, $n=16)$ improved the virus conversion at day 3 and later (control vs. HCQ, 6\% vs. 50\%, $p=0.005$ ) [42].

Cytokine Storm Blockades: Anti-TMPRSS2, Recombinant Human ACE2, ARB/ACE Inhibitors, JAK-STAT Inhibitor, Akt Pathway Inhibitor, and Anti-IL-6

As described above, virus infection via the host ACE2 induces the release of IL-6 via AT1Rs and the JAK-STAT and Akt pathways, leading to the amplification of the virus. As of the end of May 2020, there have been only retrospective studies of reagents used to treat SARS-CoV-2. Anti-TMPRSS2 agents can inhibit the cleavage of the $\mathrm{S}$ protein of this virus before its attachment. A high dose $(100 \mathrm{mg} / \mathrm{mL})$ of camostat mesylate was reported to inhibit the attachment of the $\mathrm{S}$ protein of SARSCoV-2 to cells and that TMPRSS2 reduced the growth of SARS-CoV-2 in vitro [60].

One retrospective clinical study reported that anticoagulant therapy with heparin improved the mortality rate among 449 severe COVID-19 patients with severe coagulopathy (D-dimer $>3.0 \mu \mathrm{g} / \mathrm{mL}, 32.8 \% v s .52 .4 \%, p=0.017$ ) [150]. Other studies showed that recombinant human ACE2 (rhACE2) was able to inhibit SARS-CoV-2 attachment to the host ACE2 by binding to the virus $\mathrm{S}$ protein [5], suppress viral growth efficiently in vitro [100], and improve severe lung inflammation in vivo [62]. The safety of rhACE2 has been confirmed by phase II/III studies with 39 ARDS patients (NCT01597635) [69].
Angiotensin receptor blockers (ARBs)/ACE inhibitors (ACE-Is) are widely used for the treatment of hypertension, which is commonly observed in COVID-19 patients [48]. There is no consensus as of the end of May 2020 regarding the use of ARBs/ACE-Is in COVID-19 patients, including ARBs (losartan, telmisartan) and ACE-Is (ramipril) due to insufficient clinical data about the adverse effects and outcomes. There have been several clinical studies of the relationships between ARB/ ACE-I use and COVID-19; one case-controlled study and four retrospective studies.

The case-controlled study was of the ARB/ACEI treatment of 6272 COVID-19 patients. The study results showed that ARB/ACE-I use did not change the patients' overall outcome (adjusted odds ratio [OR] $0.95,95 \%$ CI $0.86-1.05$ for ARB, $0.96,95 \%$ CI $0.87-1.07$ for ACE-I) or the rate of critical or fatal disease (adjusted OR $0.83,95 \%$ CI $0.63-1.10$ for ARB, $0.91,95 \%$ CI $0.69-1.21$ for ACE-I) [91]. A large multinational retrospective study of 8910 patients indicated that the use of an ACE-I $(n=770$, OR $0.33,95 \%$ CI $0.20-0.54)$ or an ARB $(n=556$, OR $1.23,95 \%$ CI $0.87-1.74$ ) had no effect on the likelihood of death from COVID-19 [95].

A large retrospective single-center study of 12,594 patients showed no association between ARB/ACE-I use and the severity/mortality of COVID-19 (24.7\% vs. 24.8\%, 95\% CI - 3.5-3.5) [125], as did another retrospective study (severity $32.9 \%$ vs. $30.7 \%, p=0.65$, mortality $27.3 \%$ vs. $33.0 \%, p=0.34$ ) [84]. Two retrospective studies with $>$ 100 hospitalized patients indicated that the use of an ARB/ ACE-I had no correlation with clinical outcomes (HR 0.97, 95\% CI $0.68-1.39 ; p=0.88$ ) [154] or the severity of COVID-19 symptoms [182].

IL-6 has been considered a key factor in the cytokine storm observed in COVID-19, and it is a potential therapeutic target. Tocilizumab is an anti-IL-6 monoclonal antibody with clinical evidence in rheumatoid arthritis treatment. A single-center study reported that $80-600 \mathrm{mg}$ tocilizumab stabilized the symptoms in most of the 15 patients with moderate-to-severe COVID-19 [89]. JAK inhibitors, which were originally used as a treatment for myelofibrosis or polycythemia vera, act by a selective inhibition of JAK1/JAK2 [115]. In vitro, the JAK-STAT inhibitor baricitinib seemed to influence the viral entry and inflammation response in COVID-19 [126]. There are no reported clinical trials, retrospective studies, or case series concerning the effects of JAK-STAT inhibitors in COVDI-19 treatment. 


\section{Future Perspectives}

To date, there are no sufficient clinical data to suggest any effective treatments for COVID-19. It is necessary to gather more clinical data from controlled full-powered prospective studies. As listed on ClinicalTrials.gov., several hundred clinical trials of numerous medications are proceeding: anti-coagulants (nafamostat mesylate, camostat mesylate, heparin, enoxaparin, tinzaparin), ARBs/ ACE-Is (losartan, telmisartan, ramipril), an anti-Ang2 agent (LY3127804), anti-mIL-6R drugs (sarilumab, siltuximab, tocilizumab), anti-IL-6 medications (clazakizumab, olokizumab, sirukumab), and JAK-STAT inhibitors (ruxolitinib, baricitinib, TD-0903). The therapeutic targets considered thus far are summarized in Figs. 3 and 4.

\section{CONCLUSION}

This review has summarized the latest evidence regarding the mechanisms underlying COVID-19 and its associated multi-organ injuries and failure, plus the potential strategies for treatments to be studied/developed. Since SARS-CoV-2 binds to the host ACE2 with a subsequent release of proinflammatory cytokines, the primary infection and the characteristic symptoms can occur in the lungs and nasal airway where ACE2 and TMPRSS2 are strongly co-expressed, followed by vital organ injury due to a cytokine storm that is probably initiated by IL-6. Further clinical studies of the therapeutics for COVID-19 are urgently needed as antibody drugs and vaccines that can effectively cure the disease or tackle the SARS-CoV-2 pandemic are not yet available.

\section{AUTHOR CONTRIBUTIONS}

M.I. and J.S. drafted the manuscript, with similar contributions. Z.H. extensively revised the manuscript. A.S. and K.H. revised the manuscript. D.M. conceived the study idea. All authors contributed to the manuscript's draft.

Daqing $\mathrm{Ma}$ is the archival author.

\section{FUNDING}

This work was supported by the Westminster Medical School Research Trust and a British Journal of Anaesthesia/ Royal College of Anaesthetists project grant, London, UK.

\section{COMPLIANCE WITH ETHICAL STANDARDS}

Conflict of Interest. The authors declare that they have no conflict of interest.

Reprints. Reprints will not be available from the authors.

Open Access This article is licensed under a Creative Commons Attribution 4.0 International License, which permits use, sharing, adaptation, distribution and reproduction in any medium or format, as long as you give appropriate credit to the original author(s) and the source, provide a link to the Creative Commons licence, and indicate if changes were made. The images or other third party material in this article are included in the article's Creative Commons licence, unless indicated otherwise in a credit line to the material. If material is not included in the article's Creative Commons licence and your intended use is not permitted by statutory regulation or exceeds the permitted use, you will need to obtain permission directly from the copyright holder. To view a copy of this licence, visit http://creativecommons.org/licenses/by/4.0/.

\section{REFERENCES}

1. Anguiano, L., M. Riera, J. Pascual, J.M. Valdivielso, C. Barrios, A. Betriu, S. Mojal, E. Fernandez, M.J. Soler, and Nefrona study. 2015. Circulating angiotensin-converting enzyme 2 activity in patients with chronic kidney disease without previous history of cardiovascular disease. Nephrology, Dialysis, Transplantation 30 (7): 1176-1185. https://doi.org/10.1093/ndt/gfv025.

2. Arentz, M., E. Yim, L. Klaff, S. Lokhandwala, F.X. Riedo, M. Chong, and M. Lee. 2020. Characteristics and outcomes of 21 critically ill patients with COVID-19 in Washington state. JAMA. https://doi.org/10.1001/jama.2020.4326.

3. Banales, J.M., R.C. Huebert, T. Karlsen, M. Strazzabosco, N.F. LaRusso, and G.J. Gores. 2019. Cholangiocyte pathobiology. $\mathrm{Na}$ ture Reviews. Gastroenterology \& Hepatology 16 (5): 269-281. https://doi.org/10.1038/s41575-019-0125-y.

4. Bassi, D.E., J. Zhang, C. Renner, and A.J. Klein-Szanto. 2017. Targeting proprotein convertases in furin-rich lung cancer cells results in decreased in vitro and in vivo growth. Molecular Carcinogenesis 56 (3): 1182-1188. https://doi.org/10.1002/mc.22550.

5. Batle, D., J. Wysocki, and K. Satchell. 2020. Soluble angiotensinconverting enzyme 2: A potential approach for coronavirus infection therapy? Clinical Science (London, England) 134 (5): 543545. https://doi.org/10.1042/CS20200163.

6. Beigel, J.H., K.M. Tomashek, L.E. Dodd, A.K. Mehta, B.S. Zingman, A.C. Kalil, E. Hohmann, et al. 2020. Remdesivir for the treatment of Covid-19 - Preliminary report. The New England Journal of Medicine. https://doi.org/10.1056/NEJMoa2007764. 
7. Belouzard, S., V.C. Chu, and G.R. Whittaker. 2009. Activation of the SARS coronavirus spike protein via sequential proteolytic cleavage at two distinct sites. Proceedings of the National Academy of Sciences of the United States of America 106 (14): 58715876. https://doi.org/10.1073/pnas.0809524106.

8. Bernard-Valnet, R., B. Pizzarotti, A. Anichini, Y. Demars, E. Russo, M. Schmidhauser, J. Cerutti-Sola, A.O. Rossetti, and R. Du Pasquier. 2020. Two patients with acute meningo-encephalitis concomitant to SARS-CoV-2 infection. European Journal of Neurology. https://doi.org/10.1111/ene.14298.

9. Bertram, S., A. Heurich, H. Lavender, S. Gierer, S. Danisch, P. Perin, J.M. Lucas, P.S. Nelson, S. Pohlmann, and E.J. Soilleux. 2012. Influenza and SARS-coronavirus activating proteases TMPRSS2 and HAT are expressed at multiple sites in human respiratory and gastrointestinal tracts. PLoS One 7 (4): e35876. https://doi.org/10.1371/journal.pone.0035876.

10. Biasucci, L.M., G. Liuzzo, G. Fantuzzi, G. Caligiuri, A.G. Rebuzzi, F. Ginnetti, C.A. Dinarello, and A. Maseri. 1999. Increasing levels of interleukin (IL)-1Ra and IL-6 during the first 2 days of hospitalization in unstable angina are associated with increased risk of in-hospital coronary events. Circulation 99 (16): 2079-2084. https://doi.org/10.1161/01.cir.99.16.2079.

11. Biasucci, L.M., A. Vitelli, G. Liuzzo, S. Altamura, G. Caligiuri, C. Monaco, A.G. Rebuzzi, G. Ciliberto, and A. Maseri. 1996. Elevated levels of interleukin-6 in unstable angina. Circulation 94 (5): 874-877. https://doi.org/10.1161/01.cir.94.5.874.

12. Bitker, L., and L.M. Burrell. 2019. Classic and nonclassic reninangiotensin systems in the critically ill. Critical Care Clinics 35 (2): 213-227. https://doi.org/10.1016/j.ccc.2018.11.002.

13. Black, R.A., C.T. Rauch, C.J. Kozlosky, J.J. Peschon, J.L. Slack, M.F. Wolfson, B.J. Castner, et al. 1997. A metalloproteinase disintegrin that releases tumour-necrosis factor-alpha from cells. $\mathrm{Na}$ ture 385 (6618): 729-733. https://doi.org/10.1038/385729a0.

14. Blaser, H., C. Dostert, T.W. Mak, and D. Brenner. 2016. TNF and ROS crosstalk in inflammation. Trends in Cell Biology 26 (4): 249-261. https://doi.org/10.1016/j.tcb.2015.12.002.

15. Bouadma, L., F.X. Lescure, J.C. Lucet, Y. Yazdanpanah, and J.F. Timsit. 2020. Severe SARS-CoV-2 infections: Practical considerations and management strategy for intensivists. Intensive Care Medicine 46 (4): 579-582. https://doi.org/10.1007/s00134-020-05967-x.

16. Budden, K.F., S.L. Gellatly, D.L. Wood, M.A. Cooper, M. Morrison, P. Hugenholtz, and P.M. Hansbro. 2017. Emerging pathogenic links between microbiota and the gut-lung axis. Nature Reviews. Microbiology 15 (1): 55-63. https://doi.org/10.1038/nrmicro.2016.142.

17. Cao, B., Y. Wang, D. Wen, W. Liu, J. Wang, G. Fan, L. Ruan, et al. 2020. A trial of lopinavir-ritonavir in adults hospitalized with severe covid-19. The New England Journal of Medicine 382 (19): 1787-1799. https://doi.org/10.1056/NEJMoa2001282.

18. Chen, M.M., E.A. Ashley, D.X. Deng, A. Tsalenko, A. Deng, R. Tabibiazar, A. Ben-Dor, et al. 2003. Novel role for the potent endogenous inotrope apelin in human cardiac dysfunction. Circulation 108 (12): 1432-1439. https://doi.org/10.1161/ 01.CIR.0000091235.94914.75.

19. Chen, T., D. Wu, H. Chen, W. Yan, D. Yang, G. Chen, K. Ma, et al. 2020. Clinical characteristics of 113 deceased patients with coronavirus disease 2019: Retrospective study. BMJ 368: m1091. https://doi.org/10.1136/bmj.m1091.

20. Chen, Y., Y. Guo, Y. Pan, and Z.J. Zhao. 2020. Structure analysis of the receptor binding of 2019-nCoV. Biochemical and Biophysical Research Communications. https://doi.org/10.1016/ j.bbrc.2020.02.071.

21. Cheng, Y., R. Luo, K. Wang, M. Zhang, Z. Wang, L. Dong, J. Li, Y. Yao, S. Ge, and G. Xu. 2020. Kidney disease is associated with in-hospital death of patients with COVID-19. Kidney International 97 (5): 829-838. https://doi.org/10.1016/j.kint.2020.03.005.

22. Choi, B.C., and A.W. Pak. 2003. A simple approximate mathematical model to predict the number of severe acute respiratory syndrome cases and deaths. Journal of Epidemiology and Community Health 57 (10): 831-835. https://doi.org/10.1136/jech.57.10.831.

23. Chousterman, B.G., F.K. Swirski, and G.F. Weber. 2017. Cytokine storm and sepsis disease pathogenesis. Seminars in Immunopathology 39 (5): 517-528. https://doi.org/10.1007/s00281-017-0639-8.

24. Chun, H.J., Z.A. Ali, Y. Kojima, R.K. Kundu, A.Y. Sheikh, R. Agrawal, L. Zheng, et al. 2008. Apelin signaling antagonizes Ang II effects in mouse models of atherosclerosis. The Journal of Clinical Investigation 118 (10): 3343-3354. https://doi.org/ 10.1172/JCI34871.

25. Cigola, E., J. Kajstura, B. Li, L.G. Meggs, and P. Anversa. 1997. Angiotensin II activates programmed myocyte cell death in vitro. Experimental Cell Research 231 (2): 363-371. https://doi.org/ 10.1006/excr.1997.3477.

26. Cote, F., T.H. Do, L. Laflamme, J.M. Gallo, and N. Gallo-Payet. 1999. Activation of the AT(2) receptor of angiotensin II induces neurite outgrowth and cell migration in microexplant cultures of the cerebellum. The Journal of Biological Chemistry 274 (44): 31686-31692. https://doi.org/10.1074/jbc.274.44.31686.

27. Cote, F., L. Laflamme, M.D. Payet, and N. Gallo-Payet. 1998. Nitric oxide, a new second messenger involved in the action of angiotensin II on neuronal differentiation of NG108-15 cells. Endocrine Research 24 (3-4): 403-407. https://doi.org/10.3109/ 07435809809032622

28. Coutard, B., C. Valle, X. de Lamballerie, B. Canard, N.G. Seidah, and E. Decroly. 2020. The spike glycoprotein of the new coronavirus 2019-nCoV contains a furin-like cleavage site absent in $\mathrm{CoV}$ of the same clade. Antiviral Research 176: 104742. https://doi.org/ 10.1016/j.antiviral.2020.104742.

29. Cui, S., S. Chen, X. Li, S. Liu, and F. Wang. 2020. Prevalence of venous thromboembolism in patients with severe novel coronavirus pneumonia. Journal of Thrombosis and Haemostasis. https:// doi.org/10.1111/jth.14830.

30. Diao, Bo, Chenhui Wang, Yingjun Tan, Xiewan Chen, Ying Liu, Lifen Ning, Li Chen, et al. 2020. Reduction and functional exhaustion of $\mathrm{T}$ cells in patients with coronavirus disease 2019 (COVID19). Frontiers in Immunology 11. https://doi.org/10.3389/ fimmu.2020.00827.

31. Dilauro, M., J. Zimpelmann, S.J. Robertson, D. Genest, and K.D. Burns. 2010. Effect of ACE2 and angiotensin-(1-7) in a mouse model of early chronic kidney disease. American Journal of Physiology. Renal Physiology 298 (6): F1523-F1532. https://doi.org/ 10.1152/ajprenal.00426.2009.

32. Ding, Y., L. He, Q. Zhang, Z. Huang, X. Che, J. Hou, H. Wang, et al. 2004. Organ distribution of severe acute respiratory syndrome (SARS) associated coronavirus (SARS-CoV) in SARS patients: Implications for pathogenesis and virus transmission pathways. The Journal of Pathology 203 (2): 622-630. https://doi.org/ 10.1002/path. 1560

33. Doobay, M.F., L.S. Talman, T.D. Obr, X. Tian, R.L. Davisson, and E. Lazartigues. 2007. Differential expression of neuronal ACE2 in transgenic mice with overexpression of the brain renin-angiotensin system. American Journal of Physiology. Regulatory, Integrative and Comparative Physiology 292 (1): R373-R381. https://doi.org/ 10.1152/ajpregu.00292.2006.

34. Du, L., Y. He, Y. Zhou, S. Liu, B.J. Zheng, and S. Jiang. 2009. The spike protein of SARS-CoV-a target for vaccine and therapeutic development. Nature Reviews. Microbiology 7 (3): 226-236. https://doi.org/10.1038/nrmicro2090. 
35. Fan, X.F., F. Xue, Y.Q. Zhang, X.P. Xing, H. Liu, S.Z. Mao, X.X. Kong, Y.Q. Gao, S.F. Liu, and Y.S. Gong. 2015. The Apelin-APJ axis is an endogenous counterinjury mechanism in experimental acute lung injury. Chest 147 (4): 969-978. https://doi.org/10.1378/chest.14-1426.

36. Fantini, J., C. Di Scala, H. Chahinian, and N. Yahi. 2020. Structural and molecular modelling studies reveal a new mechanism of action of chloroquine and hydroxychloroquine against SARSCoV-2 infection. Int J Antimicrob Agents:105960. https://doi.org/ 10.1016/j.ijantimicag.2020.105960.

37. Force, Ards Definition Task, V.M. Ranieri, G.D. Rubenfeld, B.T. Thompson, N.D. Ferguson, E. Caldwell, E. Fan, L. Camporota, and A.S. Slutsky. 2012. Acute respiratory distress syndrome: The Berlin definition. JAMA 307 (23): 2526-2533. https://doi.org/ 10.1001/jama.2012.5669.

38. Fyhrquist, F., and O. Saijonmaa. 2008. Renin-angiotensin system revisited. Journal of Internal Medicine 264 (3): 224-236. https:// doi.org/10.1111/j.1365-2796.2008.01981.x.

39. Gao, Y., T. Li, M. Han, X. Li, D. Wu, Y. Xu, Y. Zhu, Y. Liu, X. Wang, and L. Wang. 2020. Diagnostic utility of clinical laboratory data determinations for patients with the severe COVID-19. Journal of Medical Virology. https://doi.org/10.1002/jmv.25770.

40. Garbers, C., N. Janner, A. Chalaris, M.L. Moss, D.M. Floss, D. Meyer, F. Koch-Nolte, S. Rose-John, and J. Scheller. 2011. Species specificity of ADAM10 and ADAM17 proteins in interleukin6 (IL-6) trans-signaling and novel role of ADAM10 in inducible IL-6 receptor shedding. The Journal of Biological Chemistry 286 (17): 14804-14811. https://doi.org/10.1074/jbc.M111.229393.

41. Garcia-Pavon, S., M.A. Yamazaki-Nakashimada, M. Baez, K.L. Borjas-Aguilar, and C. Murata. 2017. Kawasaki disease complicated with macrophage activation syndrome: A systematic review. Journal of Pediatric Hematology/Oncology 39 (6): 445-451. https://doi.org/10.1097/MPH.0000000000000872.

42. Gautret, P., J. C. Lagier, P. Parola, V. T. Hoang, L. Meddeb, M. Mailhe, B. Doudier et al. . 2020. Hydroxychloroquine and azithromycin as a treatment of COVID-19: Results of an open-label nonrandomized clinical trial. Int J Antimicrob Agents:105949. https:// doi.org/10.1016/j.ijantimicag.2020.105949.

43. Gierer, S., S. Bertram, F. Kaup, F. Wrensch, A. Heurich, A. Kramer-Kuhl, K. Welsch, et al. 2013. The spike protein of the emerging betacoronavirus EMC uses a novel coronavirus receptor for entry, can be activated by TMPRSS2, and is targeted by neutralizing antibodies. Journal of Virology 87 (10): 5502-5511. https://doi.org/10.1128/JVI.00128-13.

44. Gilbert, A., J. Liu, G. Cheng, C. An, K. Deo, A.M. Gorret, and X. Qin. 2019. A review of urinary angiotensin converting enzyme 2 in diabetes and diabetic nephropathy. Biochem Med (Zagreb) 29 (1): 010501. https://doi.org/10.11613/BM.2019.010501.

45. Glowacka, I., S. Bertram, M.A. Muller, P. Allen, E. Soilleux, S. Pfefferle, I. Steffen, et al. 2011. Evidence that TMPRSS2 activates the severe acute respiratory syndrome coronavirus spike protein for membrane fusion and reduces viral control by the humoral immune response. Journal of Virology 85 (9): 4122-4134. https://doi.org/ 10.1128/JVI.02232-10.

46. Goldman, J.D., D.C.B. Lye, D.S. Hui, K.M. Marks, R. Bruno, R. Montejano, C.D. Spinner, et al. 2020. Remdesivir for 5 or 10 days in patients with severe covid-19. The New England Journal of Medicine. https://doi.org/10.1056/NEJMoa2015301.

47. Grein, J., N. Ohmagari, D. Shin, G. Diaz, E. Asperges, A. Castagna, T. Feldt, et al. 2020. Compassionate use of remdesivir for patients with severe covid-19. The New England Journal of Medicine. https://doi.org/10.1056/NEJMoa2007016.

48. Guan, W.J., Z.Y. Ni, Y. Hu, W.H. Liang, C.Q. Ou, J.X. He, L. Liu, et al. 2020. Clinical characteristics of coronavirus disease 2019 in
China. The New England Journal of Medicine 382 (18): 17081720. https://doi.org/10.1056/NEJMoa2002032.

49. Gui, M., W. Song, H. Zhou, J. Xu, S. Chen, Y. Xiang, and X. Wang. 2017. Cryo-electron microscopy structures of the SARS$\mathrm{CoV}$ spike glycoprotein reveal a prerequisite conformational state for receptor binding. Cell Research 27 (1): 119-129. https:// doi.org/10.1038/cr.2016.152.

50. Guo, T., Y. Fan, M. Chen, X. Wu, L. Zhang, T. He, H. Wang, J. Wan, X. Wang, and Z. Lu. 2020. Cardiovascular implications of fatal outcomes of patients with coronavirus disease 2019 (COVID19). JAMA Cardiology. https://doi.org/10.1001/ jamacardio.2020.1017.

51. Haga, S., N. Nagata, T. Okamura, N. Yamamoto, T. Sata, N. Yamamoto, T. Sasazuki, and Y. Ishizaka. 2010. TACE antagonists blocking ACE2 shedding caused by the spike protein of SARS$\mathrm{CoV}$ are candidate antiviral compounds. Antiviral Research 85 (3): 551-555. https://doi.org/10.1016/j.antiviral.2009.12.001.

52. Haga, S., N. Yamamoto, C. Nakai-Murakami, Y. Osawa, K. Tokunaga, T. Sata, N. Yamamoto, T. Sasazuki, and Y. Ishizaka. 2008. Modulation of TNF-alpha-converting enzyme by the spike protein of SARS-CoV and ACE2 induces TNF-alpha production and facilitates viral entry. Proceedings of the National Academy of Sciences of the United States of America 105 (22): 7809-7814. https://doi.org/10.1073/pnas.0711241105.

53. Hamming, I., M.E. Cooper, B.L. Haagmans, N.M. Hooper, R. Korstanje, A.D. Osterhaus, W. Timens, A.J. Turner, G. Navis, and H. van Goor. 2007. The emerging role of ACE2 in physiology and disease. The Journal of Pathology 212 (1): 1-11. https:// doi.org/10.1002/path.2162.

54. Hamming, I., W. Timens, M.L. Bulthuis, A.T. Lely, G. Navis, and H. van Goor. 2004. Tissue distribution of ACE2 protein, the functional receptor for SARS coronavirus. A first step in understanding SARS pathogenesis. The Journal of Pathology 203 (2): 631-637. https://doi.org/10.1002/path.1570.

55. Harahsheh, A.S., N. Dahdah, J.W. Newburger, M.A. Portman, M. Piram, R. Tulloh, B.W. McCrindle, et al. 2020. Missed or delayed diagnosis of Kawasaki disease during the 2019 novel coronavirus disease (COVID-19) pandemic. The Journal of Pediatrics. https:// doi.org/10.1016/j.jpeds.2020.04.052.

56. Heink, S., N. Yogev, C. Garbers, M. Herwerth, L. Aly, C. Gasperi, V. Husterer, et al. 2017. Trans-presentation of IL- 6 by dendritic cells is required for the priming of pathogenic TH17 cells. Nature Immunology 18 (1): 74-85. https://doi.org/10.1038/ni.3632.

57. Helms, J., C. Tacquard, F. Severac, I. Leonard-Lorant, M. Ohana, X. Delabranche, H. Merdji, et al. 2020. High risk of thrombosis in patients with severe SARS-CoV-2 infection: A multicenter prospective cohort study. Intensive Care Medicine. https://doi.org/ 10.1007/s00134-020-06062-x.

58. Heurich, A., H. Hofmann-Winkler, S. Gierer, T. Liepold, O. Jahn, and S. Pohlmann. 2014. TMPRSS2 and ADAM17 cleave ACE2 differentially and only proteolysis by TMPRSS 2 augments entry driven by the severe acute respiratory syndrome coronavirus spike protein. Journal of Virology 88 (2): 1293-1307. https://doi.org/ 10.1128/JVI.02202-13.

59. Hoffmann, M., H. Kleine-Weber, and S. Pohlmann. 2020. A multibasic cleavage site in the spike protein of SARS-CoV-2 is essential for infection of human lung cells. Molecular Cell. https://doi.org/ 10.1016/j.molcel.2020.04.022.

60. Hoffmann, M., H. Kleine-Weber, S. Schroeder, N. Kruger, T. Herrler, S. Erichsen, T.S. Schiergens, et al. 2020. SARS-CoV-2 cell entry depends on ACE2 and TMPRSS2 and is blocked by a clinically proven protease inhibitor. Cell 181 (2): 271-280 e278. https://doi.org/10.1016/j.cell.2020.02.052. 
61. Huang, C., Y. Wang, X. Li, L. Ren, J. Zhao, Y. Hu, L. Zhang, et al. 2020. Clinical features of patients infected with 2019 novel coronavirus in Wuhan, China. Lancet 395 (10223): 497-506. https:// doi.org/10.1016/S0140-6736(20)30183-5.

62. Imai, Y., K. Kuba, S. Rao, Y. Huan, F. Guo, B. Guan, P. Yang, et al. 2005. Angiotensin-converting enzyme 2 protects from severe acute lung failure. Nature 436 (7047): 112-116. https://doi.org/ 10.1038/nature 03712 .

63. Ji, H.L., R. Zhao, S. Matalon, and M.A. Matthay. 2020. Elevated plasmin(ogen) as a common risk factor for COVID-19 susceptibility. Physiological Reviews 100 (3): 1065-1075. https://doi.org/ 10.1152/physrev.00013.2020.

64. Ji, Y., J. Liu, Z. Wang, and N. Liu. 2009. Angiotensin II induces inflammatory response partly via toll-like receptor 4-dependent signaling pathway in vascular smooth muscle cells. Cellular Physiology and Biochemistry 23 (4-6): 265-276. https://doi.org/ 10.1159/000218173.

65. Jia, H.P., D.C. Look, P. Tan, L. Shi, M. Hickey, L. Gakhar, M.C. Chappell, C. Wohlford-Lenane, and P.B. McCray Jr. 2009. Ectodomain shedding of angiotensin converting enzyme 2 in human airway epithelia. American Journal of Physiology. Lung Cellular and Molecular Physiology 297 (1): L84-L96. https://doi.org/ 10.1152/ajplung.00071.2009.

66. Jin, X., J.S. Lian, J.H. Hu, J. Gao, L. Zheng, Y.M. Zhang, S.R. Hao, et al. 2020. Epidemiological, clinical and virological characteristics of 74 cases of coronavirus-infected disease 2019 (COVID19) with gastrointestinal symptoms. Gut 69 (6): 1002-1009. https://doi.org/10.1136/gutjnl-2020-320926.

67. Jones, V.G., M. Mills, D. Suarez, C.A. Hogan, D. Yeh, J. Bradley Segal, E.L. Nguyen, G.R. Barsh, S. Maskatia, and R. Mathew. 2020. COVID-19 and Kawasaki disease: Novel virus and novel case. Hospital Pediatrics. https://doi.org/10.1542/hpeds.2020-0123.

68. Kawai, T., and S. Akira. 2011. Toll-like receptors and their crosstalk with other innate receptors in infection and immunity. Immunity 34 (5): 637-650. https://doi.org/10.1016/j.immuni.2011.05.006.

69. Khan, A., C. Benthin, B. Zeno, T.E. Albertson, J. Boyd, J.D. Christie, R. Hall, et al. 2017. A pilot clinical trial of recombinant human angiotensin-converting enzyme 2 in acute respiratory distress syndrome. Critical Care 21 (1): 234. https://doi.org/10.1186/ s13054-017-1823-x.

70. Kirchdoerfer, R.N., C.A. Cottrell, N. Wang, J. Pallesen, H.M. Yassine, H.L. Turner, K.S. Corbett, B.S. Graham, J.S. McLellan, and A.B. Ward. 2016. Pre-fusion structure of a human coronavirus spike protein. Nature 531 (7592): 118-121. https://doi.org/10.1038/nature17200.

71. Klein, N., F. Gembardt, S. Supe, S.M. Kaestle, H. Nickles, L. Erfinanda, X. Lei, et al. 2013. Angiotensin-(1-7) protects from experimental acute lung injury. Critical Care Medicine 41 (11): e334-e343. https://doi.org/10.1097/CCM.0b013e31828a6688.

72. Kleinz, M.J., and A.P. Davenport. 2004. Immunocytochemical localization of the endogenous vasoactive peptide apelin to human vascular and endocardial endothelial cells. Regulatory Peptides 118 (3): 119-125. https://doi.org/10.1016/j.regpep.2003.11.002.

73. Klok, F.A., Mjha Kruip, N.J.M. van der Meer, M.S. Arbous, Gommers Dampj, K.M. Kant, F.H.J. Kaptein, et al. 2020. Incidence of thrombotic complications in critically ill ICU patients with COVID-19. Thrombosis Research. https://doi.org/10.1016/ j.thromres.2020.04.013.

74. Kuba, K., Y. Imai, S. Rao, H. Gao, F. Guo, B. Guan, Y. Huan, et al. 2005. A crucial role of angiotensin converting enzyme 2 (ACE2) in SARS coronavirus-induced lung injury. Nature Medicine 11 (8): 875-879. https://doi.org/10.1038/nm1267.

75. Kuba, K., T. Sato, Y. Imai, and T. Yamaguchi. 2019. Apelin and Elabela/toddler; double ligands for APJ/Apelin receptor in heart development, physiology, and pathology. Peptides 111: 62-70. https://doi.org/10.1016/j.peptides.2018.04.011.

76. Kumar, A., R. Zarychanski, R. Pinto, D.J. Cook, J. Marshall, J. Lacroix, T. Stelfox, et al. 2009. Critically ill patients with 2009 influenza $\mathrm{A}(\mathrm{H} 1 \mathrm{~N} 1)$ infection in Canada. JAMA 302 (17): 1872 1879. https://doi.org/10.1001/jama.2009.1496.

77. Kumar, R., V.P. Singh, and K.M. Baker. 2007. The intracellular renin-angiotensin system: A new paradigm. Trends in Endocrinology and Metabolism 18 (5): 208-214. https://doi.org/10.1016/ j.tem.2007.05.001.

78. La Gruta, N.L., K. Kedzierska, J. Stambas, and P.C. Doherty. 2007. A question of self-preservation: Immunopathology in influenza virus infection. Immunology and Cell Biology 85 (2): 85-92. https://doi.org/10.1038/sj.icb.7100026.

79. Lambert, D.W., M. Yarski, F.J. Warner, P. Thornhill, E.T. Parkin, A.I. Smith, N.M. Hooper, and A.J. Turner. 2005. Tumor necrosis factor-alpha convertase (ADAM17) mediates regulated ectodomain shedding of the severe-acute respiratory syndromecoronavirus (SARS-CoV) receptor, angiotensin-converting enzyme-2 (ACE2). The Journal of Biological Chemistry 280 (34): 30113-30119. https://doi.org/10.1074/jbc.M505111200.

80. Lamers, M.M., J. Beumer, J. van der Vaart, K. Knoops, J. Puschhof, T.I. Breugem, R.B.G. Ravelli, et al. 2020. SARS-CoV-2 productively infects human gut enterocytes. Science. https:// doi.org/10.1126/science.abc1669.

81. Lechien, J.R., C.M. Chiesa-Estomba, D.R. De Siati, M. Horoi, S.D. Le Bon, A. Rodriguez, D. Dequanter, et al. 2020. Olfactory and gustatory dysfunctions as a clinical presentation of mild-tomoderate forms of the coronavirus disease (COVID-19): A multicenter European study. European Archives of Oto-Rhino-Laryngology. https://doi.org/10.1007/s00405-020-05965-1.

82. Leung, P.S. 2010. Local RAS. Advances in Experimental Medicine and Biology 690: 69-87. https://doi.org/10.1007/978-90-481-9060-7 5.

83. Li, F., W. Li, M. Farzan, and S.C. Harrison. 2005. Structure of SARS coronavirus spike receptor-binding domain complexed with receptor. Science 309 (5742): 1864-1868. https://doi.org/10.1126/ science. 1116480

84. Li, J., X. Wang, J. Chen, H. Zhang, and A. Deng. 2020. Association of renin-angiotensin system inhibitors with severity or risk of death in patients with hypertension hospitalized for coronavirus disease 2019 (COVID-19) infection in Wuhan, China. JAMA Cardiol. https://doi.org/10.1001/jamacardio.2020.1624.

85. Li, K., C. Wohlford-Lenane, S. Perlman, J. Zhao, A.K. Jewell, L.R. Reznikov, K.N. Gibson-Corley, D.K. Meyerholz, and P.B. McCray Jr. 2016. Middle East respiratory syndrome coronavirus causes multiple organ damage and lethal disease in mice transgenic for human dipeptidyl peptidase 4. The Journal of Infectious Diseases 213 (5): 712-722. https://doi.org/10.1093/infdis/jiv499.

86. Lipsitch, M., T. Cohen, B. Cooper, J.M. Robins, S. Ma, L. James, G. Gopalakrishna, et al. 2003. Transmission dynamics and control of severe acute respiratory syndrome. Science 300 (5627): 19661970. https://doi.org/10.1126/science. 1086616.

87. Liu, P.P., A. Blet, D. Smyth, and H. Li. 2020. The science underlying COVID-19: Implications for the cardiovascular system. Circulation. https://doi.org/10.1161/CIRCULATIONAHA.120.047549.

88. Lukassen, S., R. L. Chua, T. Trefzer, N. C. Kahn, M. A. Schneider, T. Muley, H. Winter et al. . 2020. SARS-CoV-2 receptor ACE2 and TMPRSS2 are primarily expressed in bronchial transient secretory cells. EMBO J:e105114. https://doi.org/10.15252/embj.20105114.

89. Luo, P., Y. Liu, L. Qiu, X. Liu, D. Liu, and J. Li. 2020. Tocilizumab treatment in COVID-19: A single center experience. Journal of Medical Virology. https://doi.org/10.1002/jmv.25801. 
90. Mahevas, M., V.T. Tran, M. Roumier, A. Chabrol, R. Paule, C. Guillaud, E. Fois, et al. 2020. Clinical efficacy of hydroxychloroquine in patients with covid-19 pneumonia who require oxygen: Observational comparative study using routine care data. $B M J 369$ : m1844. https://doi.org/10.1136/bmj.m1844.

91. Mancia, G., F. Rea, M. Ludergnani, G. Apolone, and G. Corrao. 2020. Renin-angiotensin-aldosterone system blockers and the risk of Covid-19. The New England Journal of Medicine. https:// doi.org/10.1056/NEJMoa2006923.

92. Mao, L., H. Jin, M. Wang, Y. Hu, S. Chen, Q. He, J. Chang, et al. 2020. Neurologic manifestations of hospitalized patients with coronavirus disease 2019 in Wuhan. China. JAMA Neurol. https:// doi.org/10.1001/jamaneurol.2020.1127.

93. McCray, P.B., Jr., L. Pewe, C. Wohlford-Lenane, M. Hickey, L. Manzel, L. Shi, J. Netland, et al. 2007. Lethal infection of K18hACE2 mice infected with severe acute respiratory syndrome coronavirus. Journal of Virology 81 (2): 813-821. https://doi.org/ 10.1128/JVI.02012-06.

94. Meffert, S., M. Stoll, U.M. Steckelings, S.P. Bottari, and T. Unger. 1996. The angiotensin II AT2 receptor inhibits proliferation and promotes differentiation in PC12W cells. Molecular and Cellular Endocrinology 122 (1): 59-67. https://doi.org/10.1016/03037207(96)03873-7.

95. Mehra, M.R., S.S. Desai, S. Kuy, T.D. Henry, and A.N. Patel. 2020. Cardiovascular disease, drug therapy, and mortality in Covid-19. The New England Journal of Medicine. https://doi.org/ 10.1056/NEJMoa2007621.

96. Mehra, Mandeep R., Sapan S. Desai, Frank Ruschitzka, and Amit N. Patel. 2020. Hydroxychloroquine or chloroquine with or without a macrolide for treatment of COVID-19: A multinational registry analysis. The Lancet. https://doi.org/10.1016/s01406736(20)31180-6.

97. Mehta, P., D.F. McAuley, M. Brown, E. Sanchez, R.S. Tattersall, J.J. Manson, and U. K. Hlh Across Speciality Collaboration. 2020. COVID-19: Consider cytokine storm syndromes and immunosuppression. Lancet 395 (10229): 1033-1034. https://doi.org/10.1016/ S0140-6736(20)30628-0.

98. Mihara, M., M. Hashizume, H. Yoshida, M. Suzuki, and M. Shiina. 2012. IL-6/IL-6 receptor system and its role in physiological and pathological conditions. Clinical Science (London, England) 122 (4): 143-159. https://doi.org/10.1042/CS20110340.

99. Millet, J.K., and G.R. Whittaker. 2015. Host cell proteases: Critical determinants of coronavirus tropism and pathogenesis. Virus Research 202: 120-134. https://doi.org/10.1016/ j.virusres.2014.11.021.

100. Monteil, V., H. Kwon, P. Prado, A. Hagelkruys, R.A. Wimmer, M. Stahl, A. Leopoldi, et al. 2020. Inhibition of SARS-CoV-2 infections in engineered human tissues using clinical-grade soluble human ACE2. Cell. https://doi.org/10.1016/j.cell.2020.04.004.

101. Moore, J.B., and C.H. June. 2020. Cytokine release syndrome in severe COVID-19. Science 368 (6490): 473-474. https://doi.org/ 10.1126/science.abb8925.

102. Moriguchi, T., N. Harii, J. Goto, D. Harada, H. Sugawara, J. Takamino, M. Ueno, et al. 2020. A first case of meningitis/ encephalitis associated with SARS-Coronavirus-2. International Journal of Infectious Diseases 94: 55-58. https://doi.org/10.1016/ j.ijid.2020.03.062.

103. Murakami, M., M. Harada, D. Kamimura, H. Ogura, Y. Okuyama, N. Kumai, A. Okuyama, et al. 2013. Disease-association analysis of an inflammation-related feedback loop. Cell Reports 3 (3): 946959. https://doi.org/10.1016/j.celrep.2013.01.028.

104. Muus, Christoph, Malte D. Luecken, Gokcen Eraslan, Avinash Waghray, Graham Heimberg, Lisa Sikkema, Yoshihiko Kobayashi et al. . 2020. Integrated analyses of single-cell atlases reveal age, gender, and smoking status associations with cell type-specific expression of mediators of SARS-CoV-2 viral entry and highlights inflammatory programs in putative target cells. https://doi.org/ 10.1101/2020.04.19.049254.

105. Naka, T., M. Narazaki, M. Hirata, T. Matsumoto, S. Minamoto, A. Aono, N. Nishimoto, et al. 1997. Structure and function of a new STAT-induced STAT inhibitor. Nature 387 (6636): 924-929. https://doi.org/10.1038/43219.

106. Nataraj, C., M.I. Oliverio, R.B. Mannon, P.J. Mannon, L.P. Audoly, C.S. Amuchastegui, P. Ruiz, O. Smithies, and T.M. Coffman. 1999. Angiotensin II regulates cellular immune responses through a calcineurin-dependent pathway. The Journal of Clinical Investigation 104 (12): 1693-1701. https://doi.org/10.1172/JCI7451.

107. Netland, J., D.K. Meyerholz, S. Moore, M. Cassell, and S. Perlman. 2008. Severe acute respiratory syndrome coronavirus infection causes neuronal death in the absence of encephalitis in mice transgenic for human ACE2. Journal of Virology 82 (15): 7264 7275. https://doi.org/10.1128/JVI.00737-08.

108. Ohtsu, H., P.J. Dempsey, G.D. Frank, E. Brailoiu, S. Higuchi, H. Suzuki, H. Nakashima, K. Eguchi, and S. Eguchi. 2006. ADAM17 mediates epidermal growth factor receptor transactivation and vascular smooth muscle cell hypertrophy induced by angiotensin II. Arteriosclerosis, Thrombosis, and Vascular Biology 26 (9): e133e137. https://doi.org/10.1161/01.ATV.0000236203.90331.d0.

109. Okba, N.M.A., M.A. Muller, W. Li, C. Wang, C.H. GeurtsvanKessel, V.M. Corman, M.M. Lamers, et al. 2020. Severe acute respiratory syndrome coronavirus 2-specific antibody responses in coronavirus disease 2019 patients. Emerging Infectious Diseases 26 (7). https://doi.org/10.3201/eid2607.200841.

110. Oudit, G.Y., Z. Kassiri, C. Jiang, P.P. Liu, S.M. Poutanen, J.M. Penninger, and J. Butany. 2009. SARS-coronavirus modulation of myocardial ACE2 expression and inflammation in patients with SARS. European Journal of Clinical Investigation 39 (7): 618625. https://doi.org/10.1111/j.1365-2362.2009.02153.x.

111. Palasca, O., A. Santos, C. Stolte, J. Gorodkin, and L. J. Jensen. 2018. TISSUES 2.0: An integrative web resource on mammalian tissue expression. Database (Oxford) 2018. https://doi.org/ 10.1093/database/bay003.

112. Palazuelos, J., H.C. Crawford, M. Klingener, B. Sun, J. Karelis, E.W. Raines, and A. Aguirre. 2014. TACE/ADAM17 is essential for oligodendrocyte development and CNS myelination. The Journal of Neuroscience 34 (36): 11884-11896. https://doi.org/ 10.1523/JNEUROSCI.1220-14.2014.

113. Pan, L., M. Mu, P. Yang, Y. Sun, R. Wang, J. Yan, P. Li, et al. 2020. Clinical characteristics of COVID-19 patients with digestive symptoms in Hubei, China: A descriptive, cross-sectional, multicenter study. Am J Gastroenterol 115 (5): 766-773. https://doi.org/ 10.14309/ajg.0000000000000620.

114. Pan, X.W., D. Xu, H. Zhang, W. Zhou, L.H. Wang, and X.G. Cui. 2020. Identification of a potential mechanism of acute kidney injury during the COVID-19 outbreak: A study based on singlecell transcriptome analysis. Intensive Care Medicine. https:// doi.org/10.1007/s00134-020-06026-1.

115. Pardanani, A., and A. Tefferi. 2011. Targeting myeloproliferative neoplasms with JAK inhibitors. Current Opinion in Hematology 18 (2): 105-110. https://doi.org/10.1097/ MOH.0b013e3283439964.

116. Patel, V.B., N. Clarke, Z. Wang, D. Fan, N. Parajuli, R. Basu, B. Putko, Z. Kassiri, A.J. Turner, and G.Y. Oudit. 2014. Angiotensin II induced proteolytic cleavage of myocardial ACE2 is mediated by TACE/ADAM-17: A positive feedback mechanism in the RAS. 
Journal of Molecular and Cellular Cardiology 66: 167-176. https://doi.org/10.1016/j.yjmcc.2013.11.017.

117. Paul, M., A. Poyan Mehr, and R. Kreutz. 2006. Physiology of local renin-angiotensin systems. Physiological Reviews 86 (3): 747-803. https://doi.org/10.1152/physrev.00036.2005.

118. Peach, M.J. 1977. Renin-angiotensin system: Biochemistry and mechanisms of action. Physiological Reviews 57 (2): 313-370. https://doi.org/10.1152/physrev.1977.57.2.313.

119. Poyiadji, N., G. Shahin, D. Noujaim, M. Stone, S. Patel, and B. Griffith. 2020. COVID-19-associated acute hemorrhagic necrotizing encephalopathy: CT and MRI features. Radiology:201187. https://doi.org/10.1148/radiol.2020201187.

120. Qaradakhi, T., V. Apostolopoulos, and A. Zulli. 2016. Angiotensin (1-7) and alamandine: Similarities and differences. Pharmacological Research 111: 820-826. https://doi.org/10.1016/ j.phrs.2016.07.025.

121. Qi, F., S. Qian, S. Zhang, and Z. Zhang. 2020. Single cell RNA sequencing of 13 human tissues identify cell types and receptors of human coronaviruses. Biochemical and Biophysical Research Communications 526 (1): 135-140. https://doi.org/10.1016/ j.bbrc.2020.03.044.

122. Qin, C., L. Zhou, Z. Hu, S. Zhang, S. Yang, Y. Tao, C. Xie, et al. 2020. Dysregulation of immune response in patients with COVID19 in Wuhan, China. Clinical Infectious Diseases. https://doi.org/ $10.1093 / \mathrm{cid} / \mathrm{ciaa} 248$.

123. Ranjbar, R., M. Shafiee, A. Hesari, G.A. Ferns, F. Ghasemi, and A. Avan. 2019. The potential therapeutic use of renin-angiotensin system inhibitors in the treatment of inflammatory diseases. Journal of Cellular Physiology 234 (3): 2277-2295. https://doi.org/ $10.1002 /$ jcp. 27205.

124. Rastaldo, R., S. Cappello, A. Folino, G.N. Berta, A.E. Sprio, G. Losano, M. Samaja, and P. Pagliaro. 2011. Apelin-13 limits infarct size and improves cardiac postischemic mechanical recovery only if given after ischemia. American Journal of Physiology. Heart and Circulatory Physiology 300 (6): H2308-H2315. https://doi.org/ 10.1152/ajpheart.01177.2010.

125. Reynolds, H.R., S. Adhikari, C. Pulgarin, A.B. Troxel, E. Iturrate, S.B. Johnson, A. Hausvater, et al. 2020. Renin-angiotensinaldosterone system inhibitors and risk of Covid-19. The New England Journal of Medicine. https://doi.org/10.1056/ NEJMoa2008975.

126. Richardson, P., I. Griffin, C. Tucker, D. Smith, O. Oechsle, A. Phelan, and J. Stebbing. 2020. Baricitinib as potential treatment for 2019-nCoV acute respiratory disease. Lancet 395 (10223): e30e31. https://doi.org/10.1016/S0140-6736(20)30304-4.

127. Richardson, S., J.S. Hirsch, M. Narasimhan, J.M. Crawford, T. McGinn, K.W. Davidson, Covid-Research Consortium and the Northwell, et al. 2020. Presenting characteristics, comorbidities, and outcomes among 5700 patients hospitalized with COVID-19 in the New York City area. JAMA. https://doi.org/10.1001/ jama.2020.6775.

128. Riley, S., C. Fraser, C.A. Donnelly, A.C. Ghani, L.J. Abu-Raddad, A.J. Hedley, G.M. Leung, et al. 2003. Transmission dynamics of the etiological agent of SARS in Hong Kong: Impact of public health interventions. Science 300 (5627): 1961-1966. https:// doi.org/10.1126/science.1086478.

129. Riphagen, S., X. Gomez, C. Gonzalez-Martinez, N. Wilkinson, and P. Theocharis. 2020. Hyperinflammatory shock in children during COVID-19 pandemic. Lancet. https://doi.org/10.1016/S01406736(20)31094-1.

130. Rose-John, S. 2012. IL-6 trans-signaling via the soluble IL-6 receptor: Importance for the pro-inflammatory activities of IL-6.
International Journal of Biological Sciences 8 (9): 1237-1247. https://doi.org/10.7150/ijbs.4989.

131. Rose-John, S., J. Scheller, G. Elson, and S.A. Jones. 2006. Interleukin- 6 biology is coordinated by membrane-bound and soluble receptors: Role in inflammation and cancer. Journal of Leukocyte Biology 80 (2): 227-236. https://doi.org/10.1189/ jlb.1105674.

132. Ruan, Q., K. Yang, W. Wang, L. Jiang, and J. Song. 2020. Clinical predictors of mortality due to COVID-19 based on an analysis of data of 150 patients from Wuhan, China. Intensive Care Medicine. https://doi.org/10.1007/s00134-020-05991-x.

133. Sama, I.E., A. Ravera, B.T. Santema, H. van Goor, J.M. Ter Maaten, J.G.F. Cleland, M. Rienstra, et al. 2020. Circulating plasma concentrations of angiotensin-converting enzyme 2 in men and women with heart failure and effects of renin-angiotensinaldosterone inhibitors. European Heart Journal 41 (19): 18101817. https://doi.org/10.1093/eurheartj/ehaa373.

134. Sato, T., T. Suzuki, H. Watanabe, A. Kadowaki, A. Fukamizu, P.P. Liu, A. Kimura, et al. 2013. Apelin is a positive regulator of ACE2 in failing hearts. The Journal of Clinical Investigation 123 (12): 5203-5211. https://doi.org/10.1172/JCI69608.

135. Savarino, A., L. Di Trani, I. Donatelli, R. Cauda, and A. Cassone. 2006. New insights into the antiviral effects of chloroquine. The Lancet Infectious Diseases 6 (2): 67-69. https://doi.org/10.1016/ S1473-3099(06)70361-9.

136. Schultze, J.L., A. Schmieder, and S. Goerdt. 2015. Macrophage activation in human diseases. Seminars in Immunology 27 (4): 249-256. https://doi.org/10.1016/j.smim.2015.07.003.

137. Shekerdemian, L.S., N.R. Mahmood, K.K. Wolfe, B.J. Riggs, C.E. Ross, C.A. McKiernan, S.M. Heidemann, et al. 2020. Characteristics and outcomes of children with coronavirus disease 2019 (COVID-19) infection admitted to US and Canadian pediatric intensive care units. JAMA Pediatrics. https://doi.org/10.1001/ jamapediatrics.2020.1948.

138. Shi, S., M. Qin, Y. Cai, T. Liu, B. Shen, F. Yang, S. Cao, et al. 2020. Characteristics and clinical significance of myocardial injury in patients with severe coronavirus disease 2019. European Heart Journal. https://doi.org/10.1093/eurheartj/ehaa408.

139. Shi, S., M. Qin, B. Shen, Y. Cai, T. Liu, F. Yang, W. Gong, et al. 2020. Association of cardiac injury with mortality in hospitalized patients with COVID-19 in Wuhan, China. JAMA Cardiol. https:// doi.org/10.1001/jamacardio.2020.0950.

140. Simmons, G., D.N. Gosalia, A.J. Rennekamp, J.D. Reeves, S.L. Diamond, and P. Bates. 2005. Inhibitors of cathepsin L prevent severe acute respiratory syndrome coronavirus entry. Proceedings of the National Academy of Sciences of the United States of America 102 (33): 11876-11881. https://doi.org/10.1073/ pnas.0505577102.

141. Simoes e Silva, A.C., K.D. Silveira, A.J. Ferreira, and M.M. Teixeira. 2013. ACE2, angiotensin-(1-7) and Mas receptor axis in inflammation and fibrosis. British Journal of Pharmacology 169 (3): 477-492. https://doi.org/10.1111/bph.12159.

142. Souza, L.L., and C.M. Costa-Neto. 2012. Angiotensin-(1-7) decreases LPS-induced inflammatory response in macrophages. Journal of Cellular Physiology 227 (5): 2117-2122. https:// doi.org/10.1002/jcp.22940.

143. Souza, L.L., J. Duchene, M. Todiras, L.C. Azevedo, C.M. CostaNeto, N. Alenina, R.A. Santos, and M. Bader. 2014. Receptor MAS protects mice against hypothermia and mortality induced by endotoxemia. Shock 41 (4): 331-336. https://doi.org/10.1097/ SHK.0000000000000115.

144. Sungnak, W., N. Huang, C. Becavin, M. Berg, R. Queen, M. Litvinukova, C. Talavera-Lopez, et al. 2020. SARS-CoV-2 entry 
factors are highly expressed in nasal epithelial cells together with innate immune genes. Nature Medicine 26 (5): 681-687. https:// doi.org/10.1038/s41591-020-0868-6.

145. Sungnak, W., N. Huang, C. Becavin, M. Berg, R. Queen, M. Litvinukova, C. Talavera-Lopez, et al. 2020. SARS-CoV-2 entry factors are highly expressed in nasal epithelial cells together with innate immune genes. Nature Medicine. https://doi.org/10.1038/ s41591-020-0868-6.

146. Takizawa, H., S. Boettcher, and M.G. Manz. 2012. Demandadapted regulation of early hematopoiesis in infection and inflammation. Blood 119 (13): 2991-3002. https://doi.org/10.1182/ blood-2011-12-380113.

147. Tanaka, T., M. Narazaki, and T. Kishimoto. 2014. IL-6 in inflammation, immunity, and disease. Cold Spring Harbor Perspectives in Biology 6 (10): a016295. https://doi.org/10.1101/ cshperspect.a016295.

148. Tang, A., Z.D. Tong, H.L. Wang, Y.X. Dai, K.F. Li, J.N. Liu, W.J. $\mathrm{Wu}$, et al. 2020. Detection of novel coronavirus by RT-PCR in stool specimen from asymptomatic child, China. Emerging Infectious Diseases 26 (6). https://doi.org/10.3201/eid2606.200301.

149. Tang, D., R. Kang, C.B. Coyne, H.J. Zeh, and M.T. Lotze. 2012. PAMPs and DAMPs: Signal 0s that spur autophagy and immunity. Immunological Reviews 249 (1): 158-175. https://doi.org/10.1111/ j.1600-065X.2012.01146.x.

150. Tang, N., H. Bai, X. Chen, J. Gong, D. Li, and Z. Sun. 2020. Anticoagulant treatment is associated with decreased mortality in severe coronavirus disease 2019 patients with coagulopathy. Journal of Thrombosis and Haemostasis 18 (5): 1094-1099. https:// doi.org/10.1111/jth.14817.

151. Tang, N., D. Li, X. Wang, and Z. Sun. 2020. Abnormal coagulation parameters are associated with poor prognosis in patients with novel coronavirus pneumonia. Journal of Thrombosis and Haemostasis 18 (4): 844-847. https://doi.org/10.1111/jth.14768.

152. Tang, W., Z. Cao, M. Han, Z. Wang, J. Chen, W. Sun, Y. Wu, et al. 2020. Hydroxychloroquine in patients with mainly mild to moderate coronavirus disease 2019: Open label, randomised controlled trial. BMJ 369: m1849. https://doi.org/10.1136/bmj.m1849.

153. Tatemoto, K., M. Hosoya, Y. Habata, R. Fujii, T. Kakegawa, M.X. Zou, Y. Kawamata, et al. 1998. Isolation and characterization of a novel endogenous peptide ligand for the human APJ receptor. Biochemical and Biophysical Research Communications 251 (2): 471-476. https://doi.org/10.1006/bbrc.1998.9489.

154. Tedeschi, S., M. Giannella, M. Bartoletti, F. Trapani, M. Tadolini, C. Borghi, and P. Viale. 2020. Clinical impact of renin-angiotensin system inhibitors on in-hospital mortality of patients with hypertension hospitalized for COVID-19. Clinical Infectious Diseases. https://doi.org/10.1093/cid/ciaa492.

155. Teijaro, J.R., K.B. Walsh, S. Cahalan, D.M. Fremgen, E. Roberts, F. Scott, E. Martinborough, R. Peach, M.B. Oldstone, and H. Rosen. 2011. Endothelial cells are central orchestrators of cytokine amplification during influenza virus infection. Cell 146 (6): 980991. https://doi.org/10.1016/j.cell.2011.08.015.

156. Teijaro, J.R., K.B. Walsh, S. Rice, H. Rosen, and M.B. Oldstone. 2014. Mapping the innate signaling cascade essential for cytokine storm during influenza virus infection. Proceedings of the National Academy of Sciences of the United States of America 111 (10): 3799-3804. https://doi.org/10.1073/pnas.1400593111.

157. Terenzi, R., M. Manetti, I. Rosa, E. Romano, F. Galluccio, S. Guiducci, L. Ibba-Manneschi, and M. Matucci-Cerinic. 2017. Angiotensin II type 2 receptor (AT2R) as a novel modulator of inflammation in rheumatoid arthritis synovium. Scientific Reports 7 (1): 13293. https://doi.org/10.1038/s41598-017-13746-w.
158. Tsai, H.J., M.H. Liao, C.C. Shih, S.M. Ka, C.M. Tsao, and C.C. Wu. 2018. Angiotensin-(1-7) attenuates organ injury and mortality in rats with polymicrobial sepsis. Critical Care 22 (1): 269. https:// doi.org/10.1186/s13054-018-2210-y.

159. Tsang, K.W., P.L. Ho, G.C. Ooi, W.K. Yee, T. Wang, M. ChanYeung, W.K. Lam, et al. 2003. A cluster of cases of severe acute respiratory syndrome in Hong Kong. The New England Journal of Medicine 348 (20): 1977-1985. https://doi.org/10.1056/ NEJMoa030666.

160. Varga, Z., A.J. Flammer, P. Steiger, M. Haberecker, R. Andermatt, A.S. Zinkernagel, M.R. Mehra, R.A. Schuepbach, F. Ruschitzka, and H. Moch. 2020. Endothelial cell infection and endotheliitis in COVID-19. Lancet 395 (10234): 1417-1418. https://doi.org/ 10.1016/S0140-6736(20)30937-5.

161. Verdoni, L., A. Mazza, A. Gervasoni, L. Martelli, M. Ruggeri, M. Ciuffreda, E. Bonanomi, and L. D'Antiga. 2020. An outbreak of severe Kawasaki-like disease at the Italian epicentre of the SARSCoV-2 epidemic: An observational cohort study. Lancet. https:// doi.org/10.1016/S0140-6736(20)31103-X.

162. Vickers, C., P. Hales, V. Kaushik, L. Dick, J. Gavin, J. Tang, K. Godbout, et al. 2002. Hydrolysis of biological peptides by human angiotensin-converting enzyme-related carboxypeptidase. The Journal of Biological Chemistry 277 (17): 14838-14843. https:// doi.org/10.1074/jbc.M200581200.

163. Villela, D., J. Leonhardt, N. Patel, J. Joseph, S. Kirsch, A. Hallberg, T. Unger, et al. 2015. Angiotensin type 2 receptor (AT2R) and receptor Mas: A complex liaison. Clinical Science (London, England) 128 (4): 227-234. https://doi.org/10.1042/CS20130515.

164. Walls, A.C., Y.J. Park, M.A. Tortorici, A. Wall, A.T. McGuire, and D. Veesler. 2020. Structure, function, and antigenicity of the SARS-CoV-2 spike glycoprotein. Cell 181 (2): 281-292 e286. https://doi.org/10.1016/j.cell.2020.02.058.

165. Walls, A.C., M.A. Tortorici, B.J. Bosch, B. Frenz, P.J.M. Rottier, F. DiMaio, F.A. Rey, and D. Veesler. 2016. Cryo-electron microscopy structure of a coronavirus spike glycoprotein trimer. Nature 531 (7592): 114-117. https://doi.org/10.1038/nature16988.

166. Wang, D., B. Hu, C. Hu, F. Zhu, X. Liu, J. Zhang, B. Wang, et al. 2020. Clinical characteristics of 138 hospitalized patients with 2019 novel coronavirus-infected pneumonia in Wuhan, China. JAMA. https://doi.org/10.1001/jama.2020.1585.

167. Wang, G., F.M. Lai, B.C. Kwan, K.B. Lai, K.M. Chow, P.K. Li, and C.C. Szeto. 2011. Expression of ACE and ACE2 in patients with hypertensive nephrosclerosis. Kidney \& Blood Pressure Research 34 (3): 141-149. https://doi.org/10.1159/000324521.

168. Wang, Y., and L. Liu. 2016. The membrane protein of severe acute respiratory syndrome coronavirus functions as a novel cytosolic pathogen-associated molecular pattern to promote Beta interferon induction via a toll-like-receptor-related TRAF3-independent mechanism. mBio 7 (1): e01872-e01815. https://doi.org/10.1128/ mBio.01872-15.

169. Wen Seow, Justine Jia, Rhea Pai, Archita Mishra, Edwin Shepherdson, Tony Kiat Hon Lim, Brian K. P. Goh, Jerry K. Y. Chan et al. 2020. scRNA-seq reveals ACE2 and TMPRSS2 expression in TROP2+ liver progenitor cells: Implications in COVID-19 associated liver dysfunction. https://doi.org/10.1101/2020.03.23.002832.

170. Weskamp, G., K. Mendelson, S. Swendeman, S. Le Gall, Y. Ma, S. Lyman, A. Hinoki, et al. 2010. Pathological neovascularization is reduced by inactivation of ADAM17 in endothelial cells but not in pericytes. Circulation Research 106 (5): 932-940. https://doi.org/ 10.1161/CIRCRESAHA.109.207415.

171. Who Mers-Cov Research, and Group. 2013. State of knowledge and data gaps of Middle East respiratory syndrome coronavirus 
(MERS-CoV) in humans. PLoS Curr 5. https://doi.org/10.1371/ currents.outbreaks.0bf719e352e7478f8ad85fa30127ddb8.

172. Wichmann, D., J.P. Sperhake, M. Lutgehetmann, S. Steurer, C. Edler, A. Heinemann, F. Heinrich, et al. 2020. Autopsy findings and venous thromboembolism in patients with COVID-19: A prospective cohort study. Annals of Internal Medicine. https:// doi.org/10.7326/M20-2003.

173. Williams, B., A.Q. Baker, B. Gallacher, and D. Lodwick. 1995. Angiotensin II increases vascular permeability factor gene expression by human vascular smooth muscle cells. Hypertension 25 (5): 913-917. https://doi.org/10.1161/01.hyp.25.5.913.

174. Wrapp, D., N. Wang, K.S. Corbett, J.A. Goldsmith, C.L. Hsieh, O. Abiona, B.S. Graham, and J.S. McLellan. 2020. Cryo-EM structure of the 2019-nCoV spike in the prefusion conformation. Science 367 (6483): 1260-1263. https://doi.org/10.1126/science.abb2507.

175. Wu, C., X. Chen, Y. Cai, J. Xia, X. Zhou, S. Xu, H. Huang, et al. 2020. Risk factors associated with acute respiratory distress syndrome and death in patients with coronavirus disease 2019 pneumonia in Wuhan, China. JAMA Internal Medicine. https://doi.org/ 10.1001/jamainternmed.2020.0994.

176. Wu, Chao, Shufa Zheng, Yu Chen, and Min Zheng. 2020. Singlecell RNA expression profiling of ACE2, the putative receptor of Wuhan 2019-nCoV, in the nasal tissue. https://doi.org/10.1101/ 2020.02.11.20022228.

177. Wu, J.T., K. Leung, and G.M. Leung. 2020. Nowcasting and forecasting the potential domestic and international spread of the 2019-nCoV outbreak originating in Wuhan, China: A modelling study. Lancet 395 (10225): 689-697. https://doi.org/10.1016/S0140-6736(20)30260-9.

178. Wu, J., X. Yang, Y.F. Zhang, S.F. Zhou, R. Zhang, X.Q. Dong, J.J. Fan, M. Liu, and X.Q. Yu. 2009. Angiotensin II upregulates Toll-like receptor 4 and enhances lipopolysaccharide-induced CD40 expression in rat peritoneal mesothelial cells. Inflammation Research 58 (8): 473 482. https://doi.org/10.1007/s00011-009-0012-z.

179. Wu, Z., and J.M. McGoogan. 2020. Characteristics of and important lessons from the coronavirus disease 2019 (COVID-19) outbreak in China: Summary of a Report of 72314 Cases From the Chinese Center for Disease Control and Prevention. JAMA. https:// doi.org/10.1001/jama.2020.2648.

180. Xie, C., L. Jiang, G. Huang, H. Pu, B. Gong, H. Lin, S. Ma, et al. 2020. Comparison of different samples for 2019 novel coronavirus detection by nucleic acid amplification tests. International Journal of Infectious Diseases 93: 264-267. https://doi.org/10.1016/j.jiid.2020.02.050.

181. Xu, J., S. Zhong, J. Liu, L. Li, Y. Li, X. Wu, Z. Li, et al. 2005. Detection of severe acute respiratory syndrome coronavirus in the brain: Potential role of the chemokine mig in pathogenesis. Clinical Infectious Diseases 41 (8): 1089-1096. https://doi.org/10.1086/444461.

182. Yang, G., Z. Tan, L. Zhou, M. Yang, L. Peng, J. Liu, J. Cai, et al. 2020. Effects of ARBs and ACEIs on virus infection, inflammatory status and clinical outcomes in COVID-19 patients with hypertension: A single center retrospective study. Hypertension. https:// doi.org/10.1161/HYPERTENSIONAHA.120.15143.

183. Yang, X., Y. Yu, J. Xu, H. Shu, J. Xia, H. Liu, Y. Wu, et al. 2020. Clinical course and outcomes of critically ill patients with SARSCoV-2 pneumonia in Wuhan, China: A single-centered, retrospective, observational study. The Lancet Respiratory Medicine 8 (5): 475-481. https://doi.org/10.1016/S2213-2600(20)30079-5.

184. Ye, J., B. Zhang, J. Xu, Q. Chang, M.A. McNutt, C. Korteweg, E. Gong, and J. Gu. 2007. Molecular pathology in the lungs of severe acute respiratory syndrome patients. The American Journal of Pathology 170 (2): 538-545. https://doi.org/10.2353/ajpath.2007.060469.
185. Ye, Q., B. Wang, and J. Mao. 2020. The pathogenesis and treatment of the 'cytokine storm' in COVID-19. The Journal of Infection 80 (6): 607-613. https://doi.org/10.1016/j.jinf.2020.03.037.

186. Yin, R., W. Feng, T. Wang, G. Chen, T. Wu, D. Chen, T. Lv, and D. Xiang. 2020. Concomitant neurological symptoms observed in a patient diagnosed with coronavirus disease 2019. Journal of Medical Virology. https://doi.org/10.1002/jmv.25888.

187. Yuan, Y., D. Cao, Y. Zhang, J. Ma, J. Qi, Q. Wang, G. Lu, et al. 2017. Cryo-EM structures of MERS-CoV and SARS-CoV spike glycoproteins reveal the dynamic receptor binding domains. $\mathrm{Na}$ ture Communications 8: 15092. https://doi.org/10.1038/ ncomms15092.

188. Zhang, J.J., X. Dong, Y.Y. Cao, Y.D. Yuan, Y.B. Yang, Y.Q. Yan, C.A. Akdis, and Y.D. Gao. 2020. Clinical characteristics of 140 patients infected with SARS-CoV-2 in Wuhan, China. Allergy. https://doi.org/10.1111/all.14238.

189. Zhang, Y.H., Y.H. Zhang, X.F. Dong, Q.Q. Hao, X.M. Zhou, Q.T Yu, S.Y. Li, et al. 2015. ACE2 and Ang-(1-7) protect endothelial cell function and prevent early atherosclerosis by inhibiting inflammatory response. Inflammation Research 64 (3-4): 253-260. https://doi.org/10.1007/s00011-015-0805-1.

190. Zhao, Yu, Zixian Zhao, Yujia Wang, Yueqing Zhou, Yu Ma, and Wei Zuo. 2020. Single-cell RNA expression profiling of ACE2, the receptor of SARS-CoV-2. https://doi.org/10.1101/ 2020.01.26.919985

191. Zhou, F., T. Yu, R. Du, G. Fan, Y. Liu, Z. Liu, J. Xiang, et al. 2020 Clinical course and risk factors for mortality of adult inpatients with COVID-19 in Wuhan, China: A retrospective cohort study. Lancet 395 (10229): 1054-1062. https://doi.org/10.1016/S01406736(20)30566-3.

192. Zhou, Lulin, Zubiao Niu, Xiaoyi Jiang, Zhengrong Zhang, You Zheng, Zhongyi Wang, Yichao Zhu, Lihua Gao, Xiaoning Wang, and Qiang Sun. 2020. Systemic analysis of tissue cells potentially vulnerable to SARS-CoV-2 infection by the protein-proofed single-cell RNA profiling of ACE2, TMPRSS2 and Furin proteases. https://doi.org/10.1101/2020.04.06.028522.

193. Zhou, P., X.L. Yang, X.G. Wang, B. Hu, L. Zhang, W. Zhang, H.R. Si, et al. 2020. A pneumonia outbreak associated with a new coronavirus of probable bat origin. Nature 579 (7798): 270-273 https://doi.org/10.1038/s41586-020-2012-7.

194. Zhu, N., D. Zhang, W. Wang, X. Li, B. Yang, J. Song, X. Zhao, et al. 2020. A novel coronavirus from patients with pneumonia in China, 2019. The New England Journal of Medicine 382 (8): 727 733. https://doi.org/10.1056/NEJMoa2001017.

195. Ziegler, C.G.K., S.J. Allon, S.K. Nyquist, I.M. Mbano, V.N. Miao, C.N. Tzouanas, Y. Cao, et al. 2020. SARS-CoV-2 receptor ACE2 is an interferon-stimulated gene in human airway epithelial cells and is detected in specific cell subsets across tissues. Cell. https:// doi.org/10.1016/j.cell.2020.04.035.

196. Zou, X., K. Chen, J. Zou, P. Han, J. Hao, and Z. Han. 2020. Singlecell RNA-seq data analysis on the receptor ACE2 expression reveals the potential risk of different human organs vulnerable to 2019-nCoV infection. Frontiers in Medicine. https://doi.org/ 10.1007/s11684-020-0754-0.

197. Zou, X., S. Li, M. Fang, M. Hu, Y. Bian, J. Ling, S. Yu, L. Jing, D. $\mathrm{Li}$, and J. Huang. 2020. Acute physiology and chronic health evaluation II score as a predictor of hospital mortality in patients of coronavirus disease 2019. Critical Care Medicine. https:// doi.org/10.1097/CCM.0000000000004411.

Publisher's Note Springer Nature remains neutral with regard to jurisdictional claims in published maps and institutional affiliations. 